\title{
Exploring the transition from natural to synthetic dyes in the production of 19th-century Central Asian ikat textiles
}

\author{
Diego Tamburini ${ }^{* *}$, Eric Breitung ${ }^{1,2}$, Chika Mori $^{1,3}$, Tomoko Kotajima ${ }^{1,4}$, Matthew L. Clarke \\ and Blythe McCarthy ${ }^{1}$
}

\begin{abstract}
This study focuses on the dye analysis of 26 ikat textiles present in the collection of the Arthur M. Sackler Gallery and originally collected by Dr. Guido Goldman with the aim to gain additional information about their provenance and dating. The investigation exploits the full potential of a multi-analytical approach, starting with a non-invasive survey of all the colors using fiber optic reflectance spectroscopy (FORS), which revealed the presence of indigo and insectbased red dyes. These data were used to select areas from which samples were taken and analyzed by high performance liquid chromatography diode array detector (HPLC-DAD). These results enabled most of the natural sources of dyes to be fully identified, including American cochineal (Dactylopius coccus), madder (probably Rubia tinctorum), lac (probably Kerria lacca), larkspur (Delphinum semibarbatum), pagoda tree flower buds (Sophora japonica), grape vine leaves (Vitis vinifera), indigo and tannins. Complex mixtures of dyes were present in most samples, as a result of both the ikat making process itself and traditional dyeing practices. Synthetic dyes were identified in 9 of the textiles. Samples were re-analyzed using HPLC-DAD coupled to mass spectrometry (HPLC-DAD-MS). Malachite green (basic green 4, C.I. 42000), fuchsine (basic violet 14, C.I. 42510), rhodamine B (basic violet 10, C.I. 45170) and methyl violet (basic violet 1, C.I. 42535) were identified, and a few other tentatively identified synthetic dyes (probably orange I, II and IV, rhodamine $6 \mathrm{G}$, patent blue $V$ and alizarin yellow $G G$ ) were detected. As the first synthesis of early synthetic dyes is well documented, their presence was used to refine the dating of these textiles. The contextualization of the results also appeared to support the stylistic assumption that more intricate and colorful designs with a higher level of complexity are dated earlier than simpler, larger and more graphic ones. The overall information acquired reveals a dynamic scenario and an interesting window into the dyers' experiments and adjustments to the economic and technological changes of the nineteenth century.
\end{abstract}

Keywords: Ikat, Central asia, Natural dyes, Early synthetic dyes, Liquid chromatography, Goldman collection

\section{Introduction}

Ikat textiles are among the most famous and recognizable fabrics worldwide and they are historically produced in several parts of the world, including Central and Southeast Asia, some Middle Eastern and African

\footnotetext{
*Correspondence: TamburiniD@si.edu

${ }^{1}$ Department of Conservation and Scientific Research, Freer Gallery of Art and Arthur M. Sackler Gallery, National Museum of Asian Art, Smithsonian Institution, 1050 Independence Ave SW, Washington, DC 20560, USA Full list of author information is available at the end of the article
}

regions, Central and South America, India and Japan. The word ikat derives from the Malaysian word mengikat, meaning "to tie": in fact, the patterns and decorations are obtained by adopting a specific process, in which bundles of threads are repeatedly bound with a resist material and dyed, in order to only fix the color in the areas left exposed. The design is therefore created in the yarns rather than on the finished cloth, which makes the process very difficult and time-consuming. The weaving is then carefully carried out after stretching the dyed
Springer Open

(c) The Author(s) 2020. This article is licensed under a Creative Commons Attribution 4.0 International License, which permits use, sharing adaptation, distribution and reproduction in any medium or format, as long as you give appropriate credit to the original author(s) and the source, provide a link to the Creative Commons licence, and indicate if changes were made. The images or other third party material in this article are included in the article's Creative Commons licence, unless indicated otherwise in a credit line to the material. If material is not included in the article's Creative Commons licence and your intended use is not permitted by statutory regulation or exceeds the permitted use, you will need to obtain permission directly from the copyright holder. To view a copy of this licence, visit http://creativeco mmons.org/licenses/by/4.0/. The Creative Commons Public Domain Dedication waiver (http://creativecommons.org/publicdomain/ zero/1.0/) applies to the data made available in this article, unless otherwise stated in a credit line to the data. 
threads on a loom in the correct order. Consequently, these textiles are patterned with a typical "blurriness" or feather-like effect, as a result of the color in the dye bath bleeding under the resist material and of the slight movement of threads caused by the strains imposed by the weaving process [1].

A significant amount of research has been conducted to track the origin of the $i k a t$ technique and highlight the cultural importance of the practice, and there is common consensus that the practice originated independently in the different continents [1-7]. Nevertheless, tracking the origin of Central Asian ikats is a complicated task, due to the scarce archaeological evidence, as well as the lack of evidence of $i k a t$ production throughout the seventeenth century. Moreover, Central Asia is a broad term referring to a vast geographical region, which has never corresponded to one political entity and whose historical importance is partially related to it being located at the heart of the Silk Road [1, 6, 7]. Although silk and sericulture were introduced from China in very ancient times, an Indian origin of the ikat-weaving technique is sometimes hypothesized [6]. Regardless of the ultimate answer to the origin of the ikat tradition, by the nineteenth century, following the domination period of the Uzbeks and before falling under the control of the Russian empire, Central Asia was producing a worldrenowned variety of $i k a t s$, and the technique was at its highest point [1]. Traditionally used as clothing for both men and women, these textiles acquired a huge role in the cultural life of the region, as they were intended for weddings and important events, as markers of status, as decorative wall-hangings, gifts and ritual objects. In addition to their functions, they have always retained an artistic expression in their own right $[1,8]$. The motifs and patterns reflect the Central Asian melting pot of people and cultures. Many motifs are pre-Islamic in origin, descending from Turkic tribal groups and carry some mystical value, such as the scorpion (poisonous, symbolic of warding off evil) and the jug of water (symbol of purity, especially to Muslims who are expected to wash before prayer). Most motifs are deeply rooted in Persian iconography and Islamic forms, such as the cypress tree, but artisans reused them, recycled them, and tweaked them, sometimes making connections with the original designs difficult. Rams' horns motifs, "eye spot" patterns, triangular amulets, arachnids, flowers and pendants reminiscent of jewelry are common Central Asian patterns. The Islamic mastery of geometrical design is also commonly showcased $[8,9]$. Some of these motifs are present on the ikats under investigation in this study and are shown in Fig. 1.

It is not surprising that such exquisite textiles attracted the attention of collectors. Among them is Dr. Guido
Goldman, who donated 76 ikat textiles from his personal collection to the Arthur M. Sackler Gallery. In a collector's note, Guido Goldman wrote “...as I purchased more ikats I had no well-formed purpose in mind other than the desire to acquire pieces that moved me. It was color and design, and to some degree condition, that determined what I bought. I avoided ikats that were chemically dyed, preferring multi-colored $i k a t s$ with relatively complex designs, which generally meant those of an earlier period" [1]. His words reveal his intention to buy traditionally-made and relatively old $i k a t s$, but also hint towards one of the main issues with these objects, which is the lack of information on their production date and provenance. Some ikats have reliable dating and provenance, such as some pieces at the State Hermitage Museum (St Petersburg, Russia), which were sent as gifts from Khans to the Russian Tsar [10], or those in the Robert Shaw collection at the Ashmolean Museum (Oxford, UK), as the exact dates of Shaw's travels are known [11]. However, the most common scenario is for the pieces to have come to the collectors through art dealers, and the original information is inevitably lost. Even when the acquisition place is recorded, the pieces may still have been made and worn elsewhere. Dating is even more problematic and is often based on the stylistic assumption that more complex and colorful designs are dated earlier than simpler and larger ones. The complexity and labor is measured in terms of how small the binds are and how frequently the color changes along a warp length, so larger and more graphic designs correspond to a simpler method of production [9].

In Bukhara and Samarkand, which are reported as the main centers of production in the nineteenth century, the making of ikats was a standardized process, which involved several workshops, and is documented by nineteenth century ethnographic literature and photos [1]. The preparation of the warp silk threads was done using a wooden wheel as measuring unit for the thread length (generally $202.5 \mathrm{~m}$ ). The number of threads in a warp was commonly 48, referred to as a livit. After a gentle boiling with potash, the whitened warps were stretched, dried and sent to the abr-bandi (ikat-binding) workshop, in which a special wooden board was used. The board contained between 40 and 60 holes evenly spaced and each livit was passed through one hole and knotted on one hand of the board. Then, two wooden beams were placed at the exact distance representing the patterning frame, and the entire length was wound around the two beams using the pierced wooden board to keep all the livits in place. The outlines of the pattern were marked with charcoal and waterproof (greased) cotton strings were tied around small bundles of threads to prevent these areas from coming into contact with the first dyestuff. After 


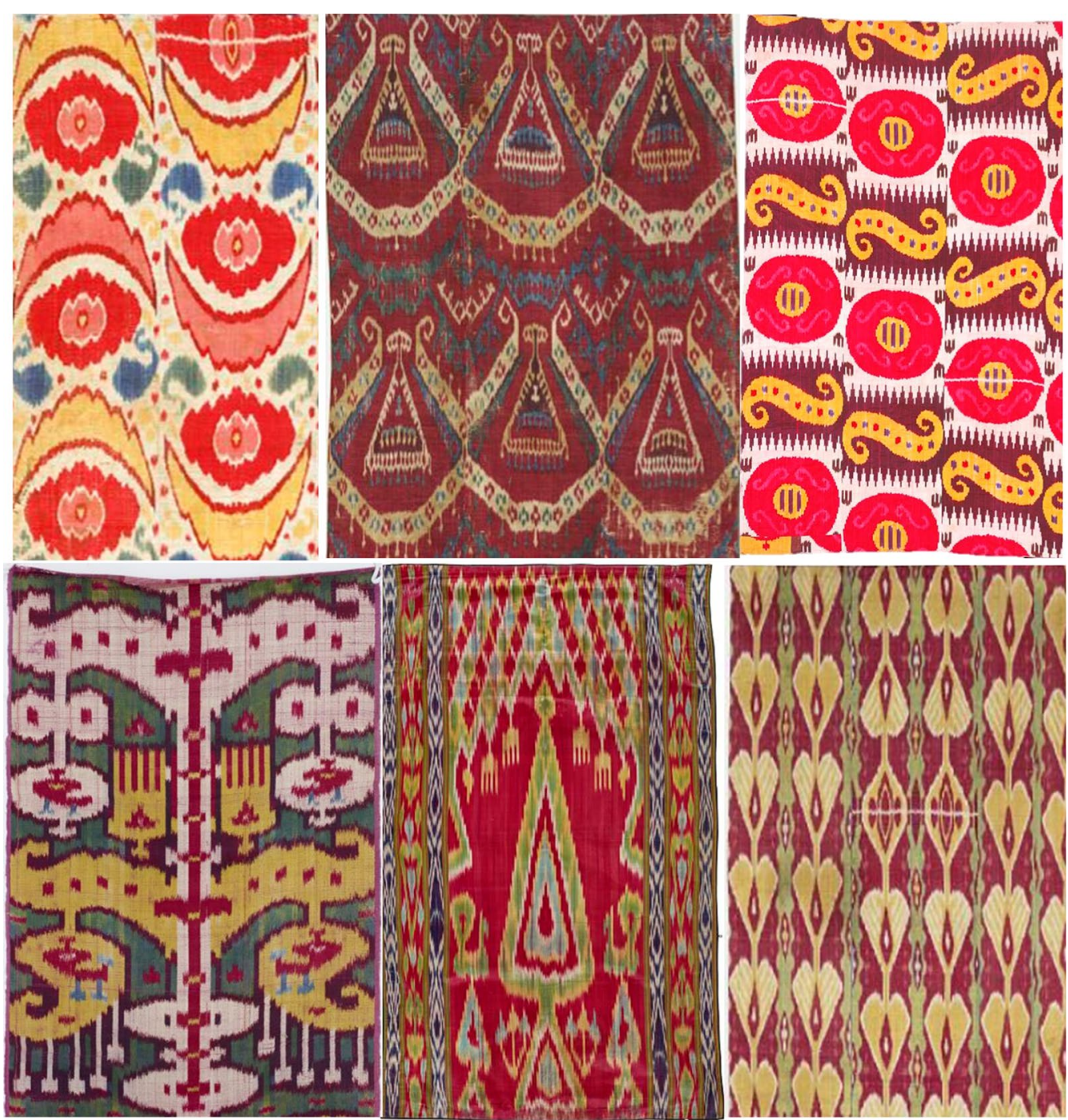

Fig. 1 Motifs present on some of the ikats investigated from the Arthur M. Sackler Gallery collection, Smithsonian Institution, Washington, DC: gifts of Guido Goldman. Top: left—crescent and flowers (S2004.66); middle—amulets (S2004.91); right—tambourines and S-curved horns (S2004.84). Bottom: left—rams' horns (S2004.78); middle_cypress trees (S2004.85); right—heart-shaped asyk or shagai, probably representing the ankle bones of a sheep or goat (S2004.92)

careful removal from the frame, the threads were sent to the dye house. Muslim dyers specialized in hot mordant dyeing with red and yellow vegetable dyes, and Jewish dyers specialized in indigo cold vat dyeing. Therefore, the threads were often dyed in at least two different places. The most prestigious and expensive type of fabric was the seven-color ikat or haftrang, obtained by immersing the warp in three subsequent dye baths: first yellow, then red, and finally dark blue. The last, over-dyed on yellow or red areas, gave green and purple shades. Between each dye bath, the threads had to return to the abr-bandi workshop and another set of binds was applied. Finally, the dyed threads were sent to the weaving workshop, where they were stretched on simple treadle looms and a plain weave fabric was generally obtained using non-patterned cotton wefts $[1,9,12]$.

Scientific analysis, in particular dye identification, provides useful information when it comes to addressing provenance and dating questions. Specific types of natural dyes are used in certain geographical areas [13-15] and are reported to be used before or after a certain date [16]. In addition, synthetic dyes were created in the second half of the nineteenth century [17], and their first synthesis is documented with precise dates $[18,19]$. Although Goldman explicitly avoided ikats that did not look naturally dyed, one of the main focuses of this study 
was to check on the presence of synthetic dyes to use them as dating tool and establish the terminus post quem production dates.

Dye analysis on Central Asian ikats is very scarce [20]. Based on previously published research, it appears that the following sources of dyes were used: madder (Rubia tinctorum) and cochineal, American cochineal (Dactylopius coccus) and possibly a local species, for red and purple, larkspur (Delphinum semibarbatum) and pagoda tree flower buds (Sophora japonica) for yellow, and indigo for blue $[1,20]$. Dyeing recipes are also reported in nineteenth century ethnographic literature and these include, in addition to the above-mentioned dyes, the use of sandalwood (Pterocarpus santalinus) and sappanwood (Caesalpinia sappan) for red and purple, as well as the use of pomegranate skin, mallow flower, rhubarb, pistachio galls and mulberry leaves as sources of tannins [1].

Analytical methods for the identification of dyes have been developed in the past decades [21]. It has been shown that high pressure liquid chromatography (HPLC) techniques have the highest potential in terms of the level of detail and accuracy that can be obtained [22]. The molecules extracted from the fibers are chromatographically separated and identified singularly, thus enabling complex mixtures to be characterized. Dye sources can often be identified down to the species of the plant or animal from which they were produced [23-27]. The molecular detection and identification is usually possible by using a diode array detector (DAD), as the typical UV-Vis absorption spectra and retention times produce sufficient information to identify the most common sources of natural dyes [28-30]. However, mass spectrometry (MS) detectors have affirmed their advantages, especially in terms of identification of degradation products and relevant non-colored molecules, so that HPLC-DADMS is largely applied to dye identification [31, 32]. More recently, the application of high resolution mass spectrometry (HRMS) and tandem mass spectrometry (MS/ MS) has opened new possibilities in terms of elucidating structures, distinguishing between isomers and identifying new sources of dyes [33-43]. In particular, these detectors are especially useful when complex isomeric mixtures are present, as they provide an additional level of separation that can sometimes not be achieved by chromatography [44].

Although the amount of sample required nowadays for HPLC analysis is minimal (2-3 $\mathrm{mm}$ of a thread), sampling is not always possible when dealing with precious and fragile textiles and non-invasive approaches are highly desirable. Non-destructive surface techniques, such as UV-Vis reflectance and luminescence spectroscopies, have been applied to identify a limited number of colorants [45-51]. Similarly, multispectral imaging (MSI) has been recently introduced as a useful tool for studying the distribution of the dyes on large surfaces with the possibility to identify selected dyes [52-55]. Nonetheless, non-invasive investigations produce limited information, especially when it comes to yellow dyes, most of which are hardly distinguishable from each other in terms of their fluorescence and reflectance spectra, or dye mixtures. As a result, recent studies have focused on the delineation of protocols aimed at identifying dyes in textiles using a combination of non-invasive techniques (microscopy, FORS and MSI), whose results can guide a selective sampling of areas of particular interest to be analyzed by HPLC techniques [40, 54, 56-58].

In this framework, our study focused on the scientific investigation of $26 \mathrm{ikat}$ textiles with the aim to identify the dyes present, using FORS to screen all the colors and select the areas to be sampled and analyzed by HPLCDAD. A further selection of samples was then made based on the suspected presence of synthetic dyes, and these samples were finally analyzed by HPLC-DAD-MS.

\section{Materials and methods Objects and samples}

The 26 ikats under investigation were originally collected by Dr. Guido Goldman and donated to the Arthur M. Sackler Gallery between 2004 and 2007. They include 19 wall hangings, 3 loom length textiles ( 1 complete and 2 sections) and 4 woman's robes (munisak). They are all warp-faced plain weave ikats with cotton wefts and silk warps, with the exception of 4 silk velvets (S2004.78, S2004.95, S2004.96 and 2007.30). They are all attributed to the nineteenth century, supposedly spanning from the beginning to the end of the century, mostly based on stylistic interpretation. For most, the geographical provenance is Uzbekistan. In some cases, they are more precisely related to Bukhara, Samarkand or the Ferghana valley, whereas in other cases a general Central Asian provenance is ascribed. The textile S2004.85 is considered Iranian, based on the typical cypress tree design, but it is not certain if it was made in Iran or in Central Asia by Iranian craftsman.

98 samples (ca. $1 \mathrm{~cm}$ of a thread corresponding to ca. $0.5 \mathrm{mg}$ ) were taken as representative of most colors exhibited. For the ikats composed of multiple panels, samples were not always taken from the same panel, as priority was given to sampling from already-damaged, easily accessible areas. Although it is generally assumed that the panels of the same $i k a t$ are from the same loom and have therefore been dyed in the same way, it is also known that different panels were sometimes sewn together, borders were added and additions were made in order to change the dimension of an ikat. As we were not able to sample all the panels of each $i k a t$, the fact that 
different dyes might be present in different panels from the same ikat should be taken into consideration when interpreting the results. The number of panels and information about whether the samples were from the same panel or not are reported in Table 1.

\section{FORS}

FORS measurements were carried out for all colored areas. Spectra were acquired using a Cary 50 ultravioletvisible spectrophotometer with a six-around-one fiber optic reflectance probe, whose instrumental details are described in [59]. Data were acquired in the range 190$950 \mathrm{~nm}$ in reflectance mode at a scan rate $120 \mathrm{~nm} / \mathrm{min}$, with $1 \mathrm{~nm}$ data interval and $0.5 \mathrm{~s}$ average time. A baseline correction was applied using a white diffuse reflectance standard (Spectralon ${ }^{\circledR}$ Calibrated Reflectance Standard \#SRS 99-010, Labsphere) Smoothing was performed using the Cary 50 software.

\section{HPLC-DAD}

All 98 samples were analyzed by HPLC-DAD. Dye extraction was performed by adding $200 \mu \mathrm{L}$ of a mixture of oxalic acid $(0.2 \mathrm{M})$, acetone, methanol and water (1:30:30:40 v:v:v:v) to the samples and then keeping them for $30 \mathrm{~min}$ at $60{ }^{\circ} \mathrm{C}$. The solution was then transferred to a $2 \mathrm{~mL}$ vial and dried under vacuum over $2-4 \mathrm{~h}$ at room temperature. The residue was reconstituted in $40 \mu \mathrm{L}$ of a mixture of methanol and water (1:1 v:v). The vial was capped and centrifuged for $10-20 \mathrm{~s}$ and $20 \mu \mathrm{L}$ of the extracts were introduced to the HPLC system via an auto-sampler.

The HPLC system was an Agilent 1100 equipped with a binary pump and a diode array (DAD) detector. Separation was achieved using a Phenomenex Kinetex C18 reversed phase column $(2.1 \mathrm{~mm} \times 100 \mathrm{~mm}, 2.6 \mu \mathrm{m}$ particle size) and a gradient of eluent A ( $1 \%$ formic acid, $5 \%$ methanol, $94 \%$ water) and eluent B (1\% formic acid in methanol) programmed as follows: initial conditions 0-0.5 min 15\% B, 0.5-25 min 15-85\% B, 25-27 min 85\% B, $27-29 \mathrm{~min} 85-15 \% \mathrm{~B}$. The flow rate was $0.25 \mathrm{~mL} / \mathrm{min}$.

Integration of chromatographic peak areas was performed at different wavelengths (optimal wavelengths are $350 \mathrm{~nm}$ for yellow molecules, $450 \mathrm{~nm}$ for red molecules, $550 \mathrm{~nm}$ for purple molecules and $600 \mathrm{~nm}$ for blue molecules) using the automatic integration function of the Chemstation (Agilent) software, in order to obtain broad estimations (percentages) of the extract content, following published methods [28]. In the case of the published data, the relative standard deviation related to this type of operation is less than $10 \%$ [28]. The percentages reported in Table 1 derive from integrations performed at $254 \mathrm{~nm}$ of all the chromatographic areas corresponding to all the molecules identified in a sample. The percentages obtained from the molecules related to the same dye source were then summed to obtain the reported values. $254 \mathrm{~nm}$ was chosen to have some internal consistency, as the detection of most relevant molecules was possible at this wavelength [20], although it is not optimal in terms of the absolute percentage values obtained, especially for blue molecules. The percentages are useful for internal comparisons among samples and should not be considered actual concentrations.

\section{HPLC-DAD-MS}

A selection of 22 samples suspected to contain synthetic dyes was re-analyzed using HPLC-DAD-MS. The extraction method used is described in [27] and briefly consisted of a single extraction using $200 \mu \mathrm{L}$ of a solution of pyridine/water/1.0 M oxalic acid in water (45:45:10 v:v:v) at $100{ }^{\circ} \mathrm{C}$ for $15 \mathrm{~min}$, followed by cooling to room temperature, evaporation to dryness and re-dissolution of the residue in $50 \mu \mathrm{L}$ of methanol/water (1:1). After final centrifugation at $12,000 \mathrm{rpm}, 30 \mu \mathrm{L}$ of the supernatant was transferred to an insert in an auto-injector vial and $20 \mu \mathrm{L}$ was injected onto the HPLC column. This extraction method, compared to the one used for HPLC-DAD, was optimized to provide good recovery for a very broad range of categories of natural and synthetic dyes [27, 60].

A Shimadzu LCMS-2020 instrument was used, consisting of an automatic injector, a gradient pump, diode array detector (DAD), electrospray ionization (ESI) interface and a quadrupole $(\mathrm{Q})$ analyzer. Operation of the system and data analysis were done using the LabSolutions software (ver. 5.1.1), and detection was carried out in both negative and positive ionization modes. The separation of the dye components was carried out using a Phenomenex Luna C18 reversed phase column (2 mm dia. $\times 150 \mathrm{~mm}$ long; $3-\mu \mathrm{m}$ particle size), operated at a flow rate of $0.18 \mathrm{~mL} / \mathrm{min}$. Elution was achieved with a linear gradient of water with $0.1 \%$ formic acid and acetonitrile with $0.1 \%$ formic acid from 18 to $95 \%$ acetonitrile. The DAD detector scanned in the range 190-800 $\mathrm{nm}$. The ESI experimental conditions were: interface voltage $4.5 \mathrm{kV}$, interface temperature $350{ }^{\circ} \mathrm{C}$, desolvation line (DL) temperature $250{ }^{\circ} \mathrm{C}$, nebulizing gas flow $1.5 \mathrm{~L} / \mathrm{min}$, drying gas flow $15 \mathrm{~L} / \mathrm{min}$, heat block temperature $200{ }^{\circ} \mathrm{C}$. MS data were acquired in the range $100-1000 \mathrm{~m} / z$ at scan speed $1875 \mathrm{u} / \mathrm{sec}$ and with Q-array RF voltage $60 \mathrm{~V}$.

For both HPLC-DAD and HPLC-DAD-MS analysis, dye components were associated with natural and synthetic dye sources using data measured from reference materials (retention times, UV-Vis spectra and mass measurements) made available by the Getty Conservation Institute (Los Angeles, USA) [61], as well as from the published literature [14, 23, 24, 27, 37, 38, 40, 44, 62-64]. 


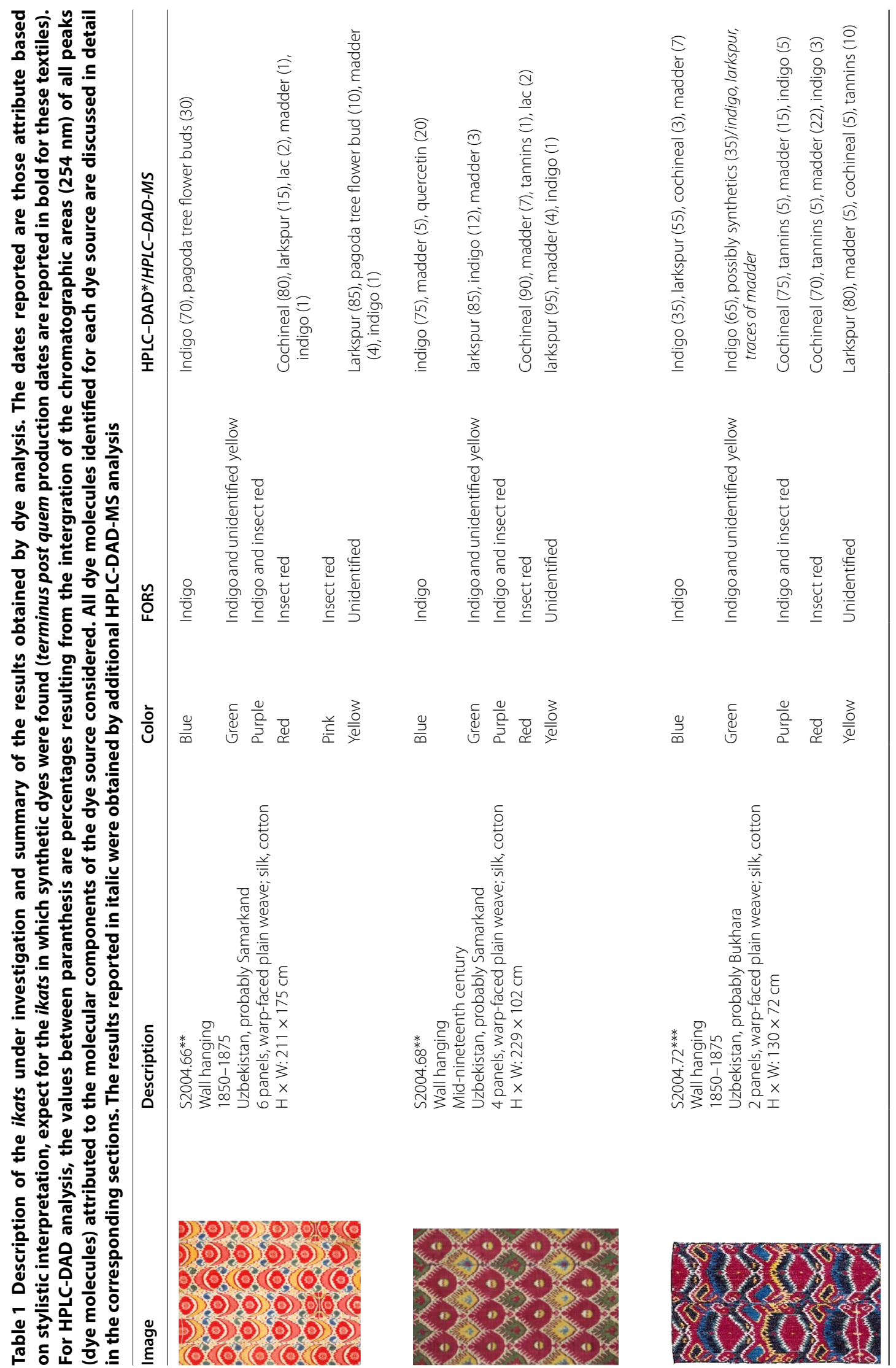




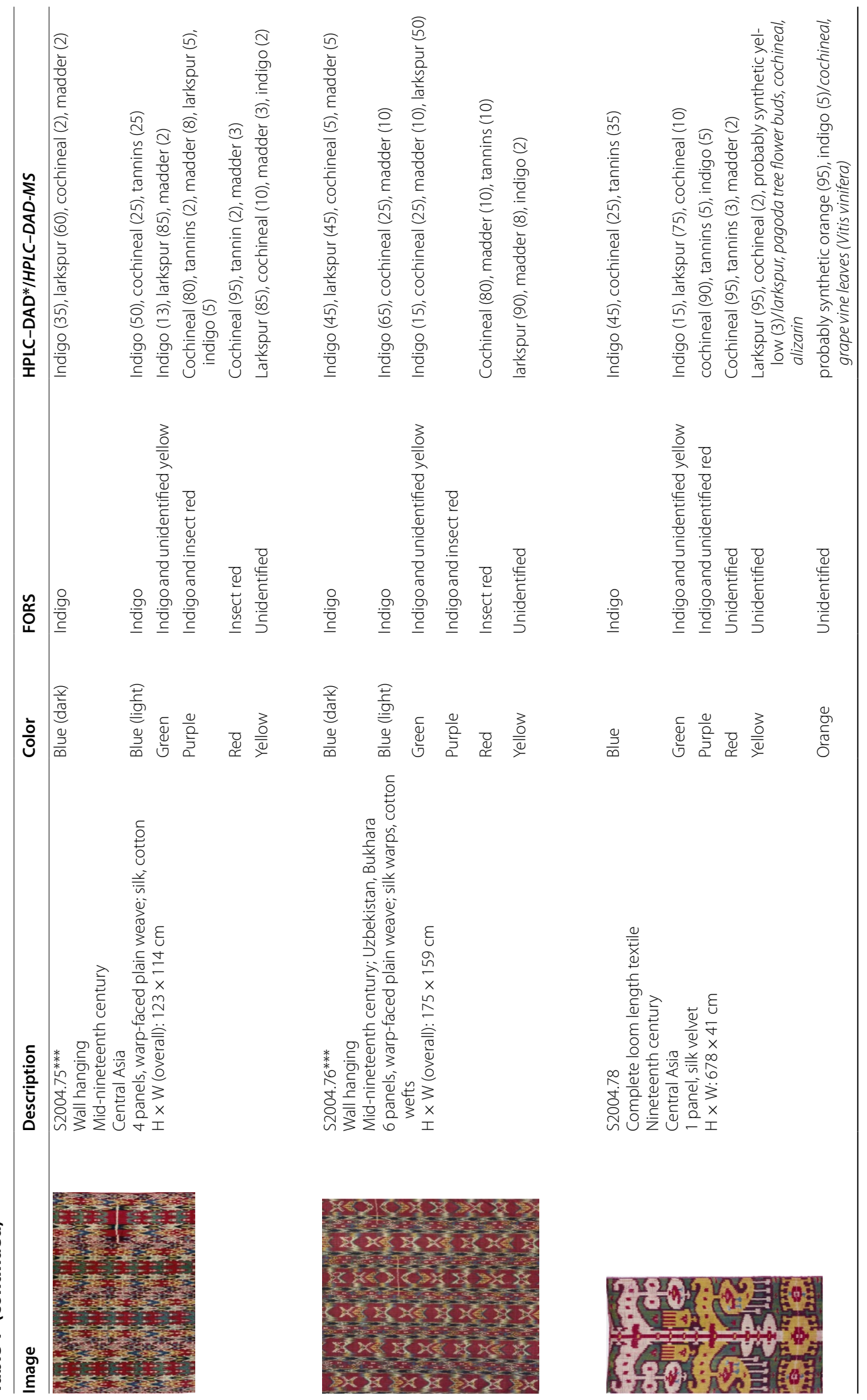




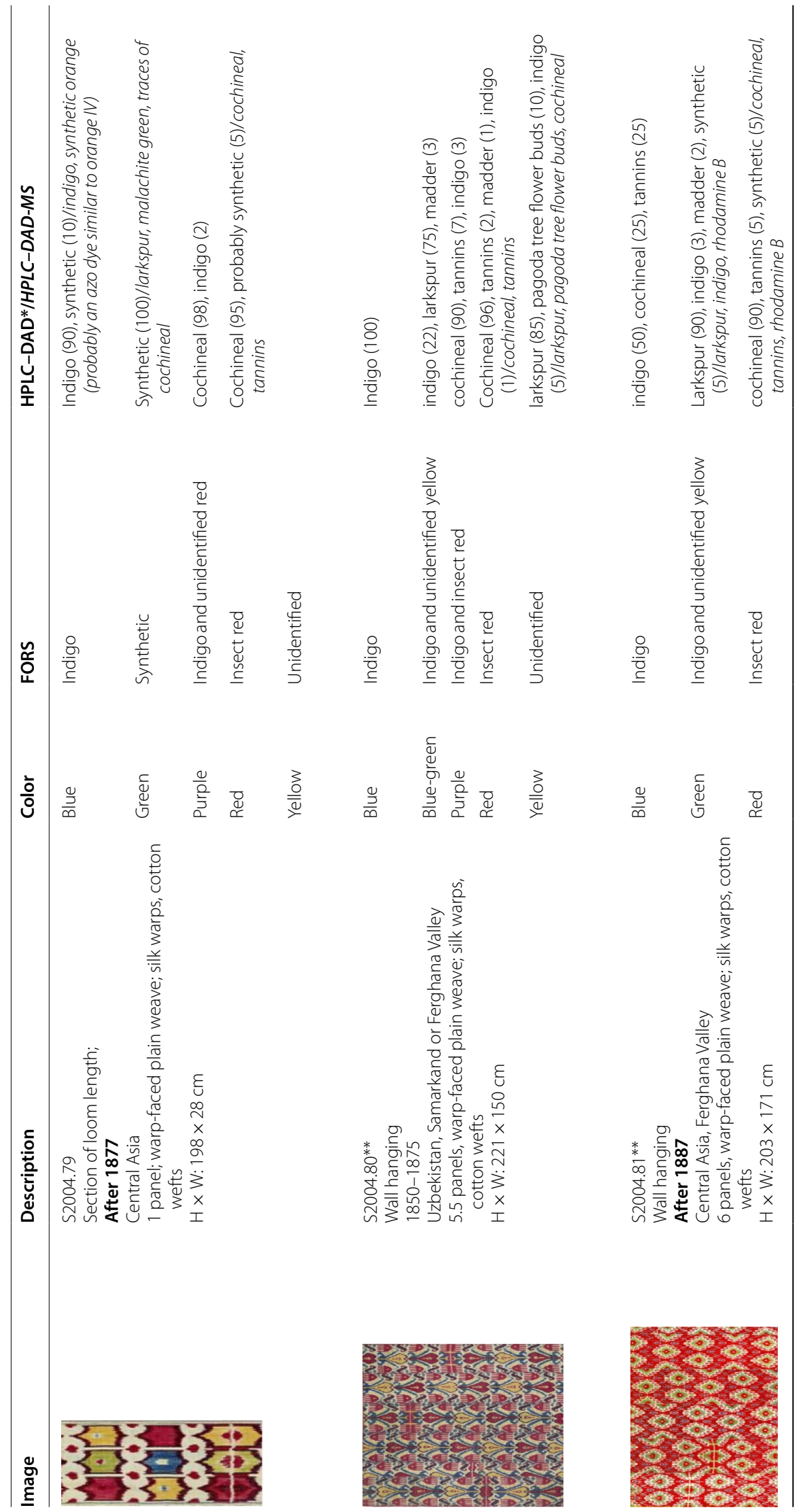



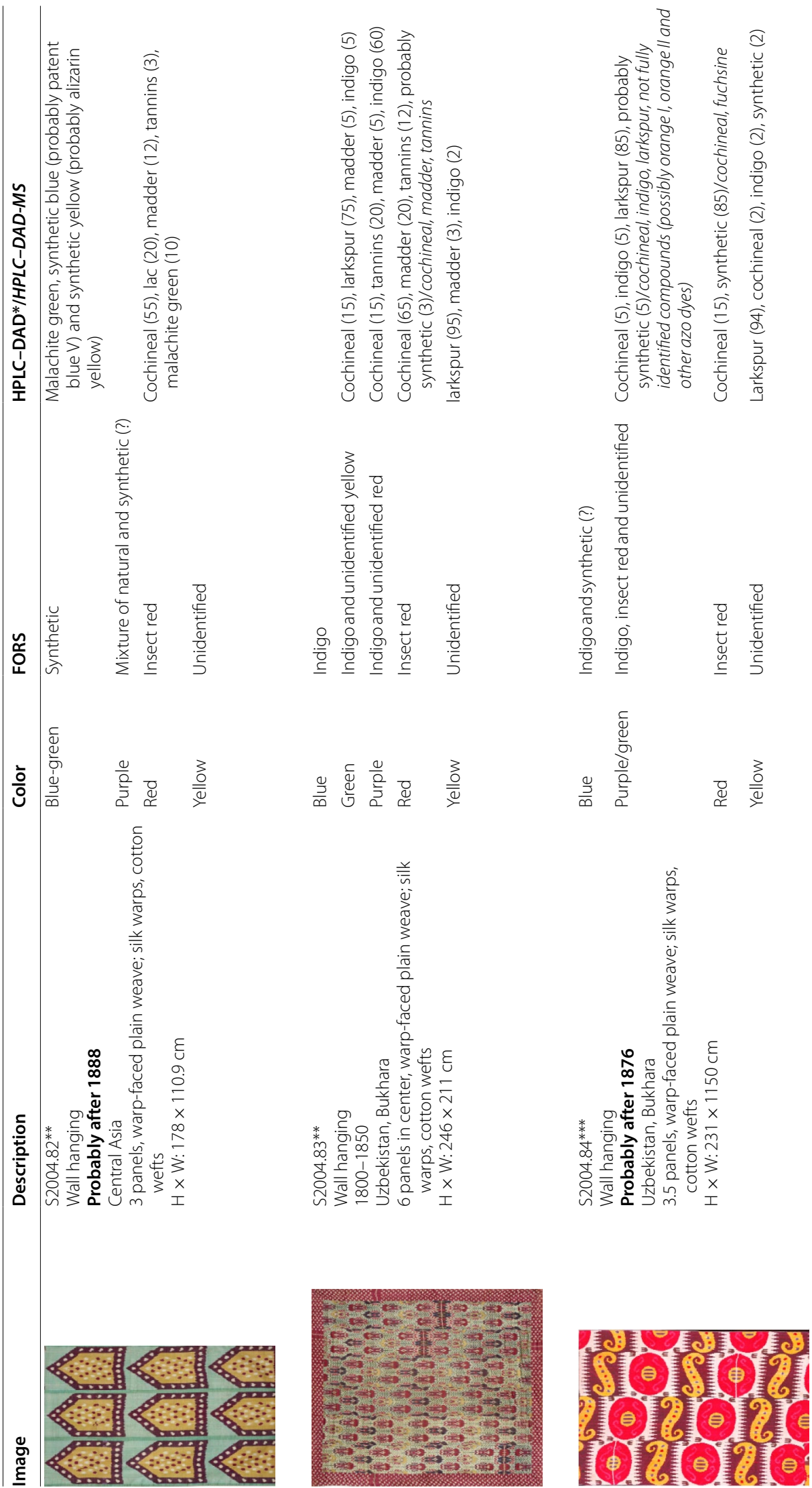

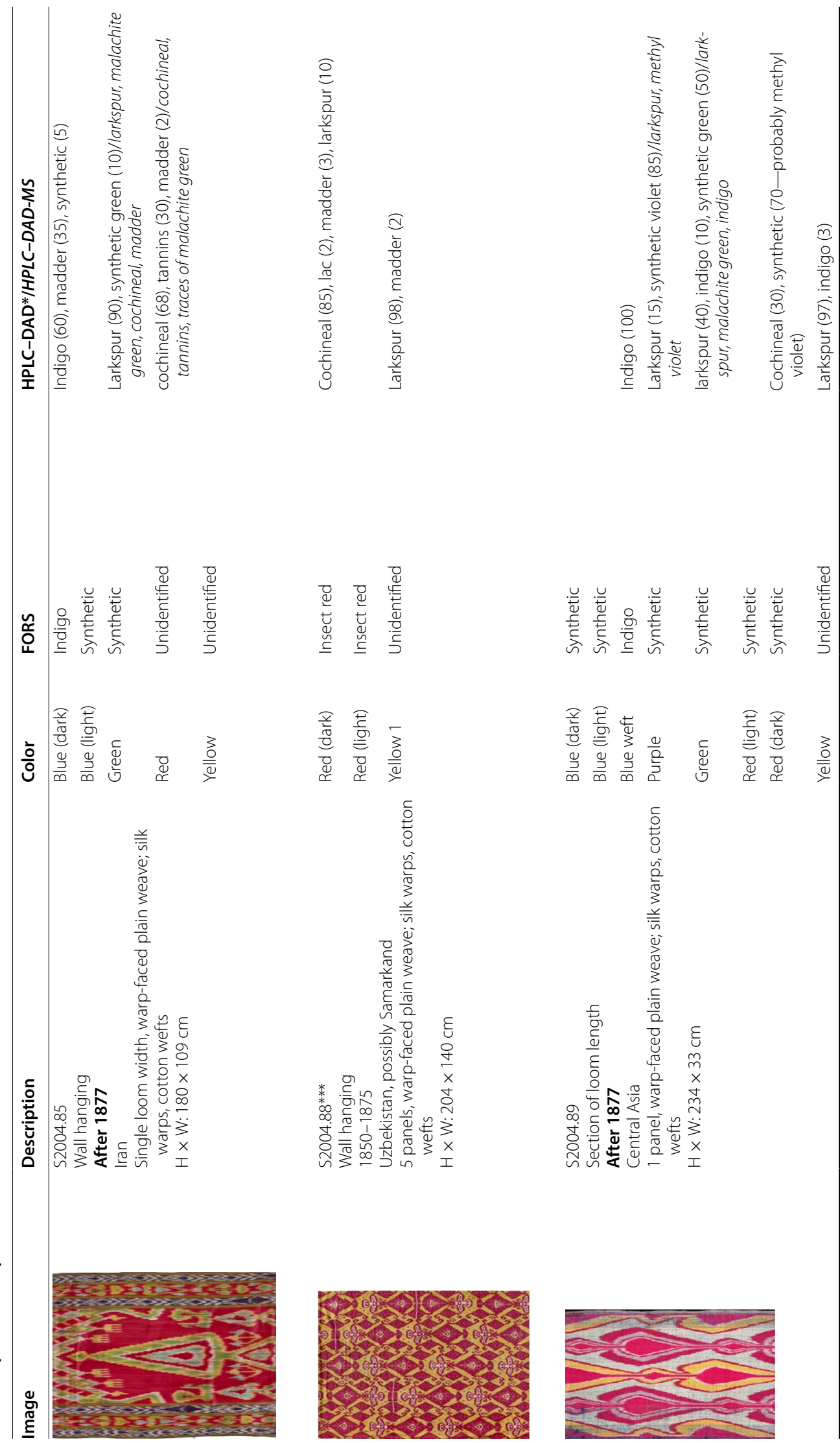

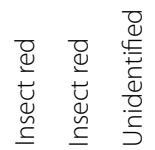

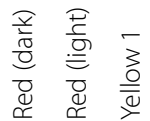
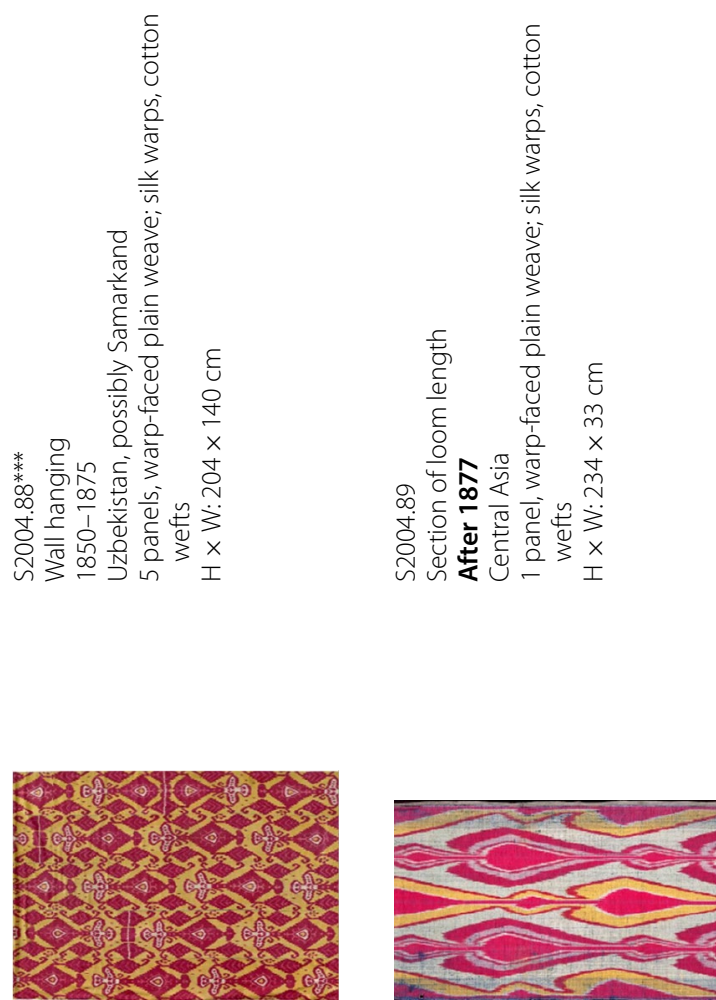
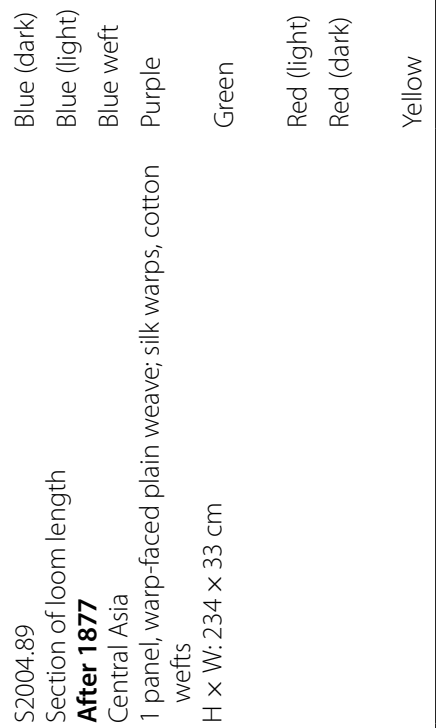


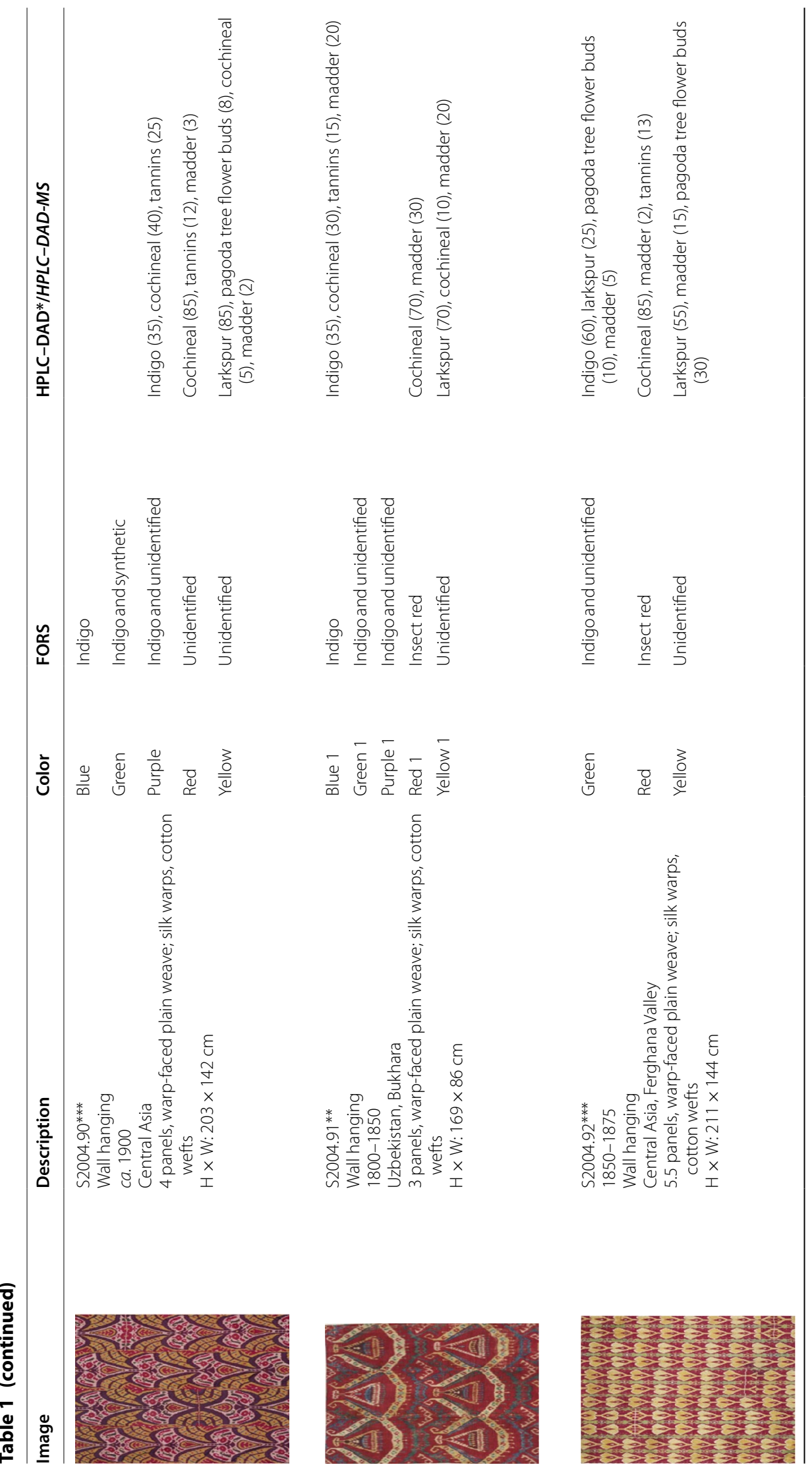




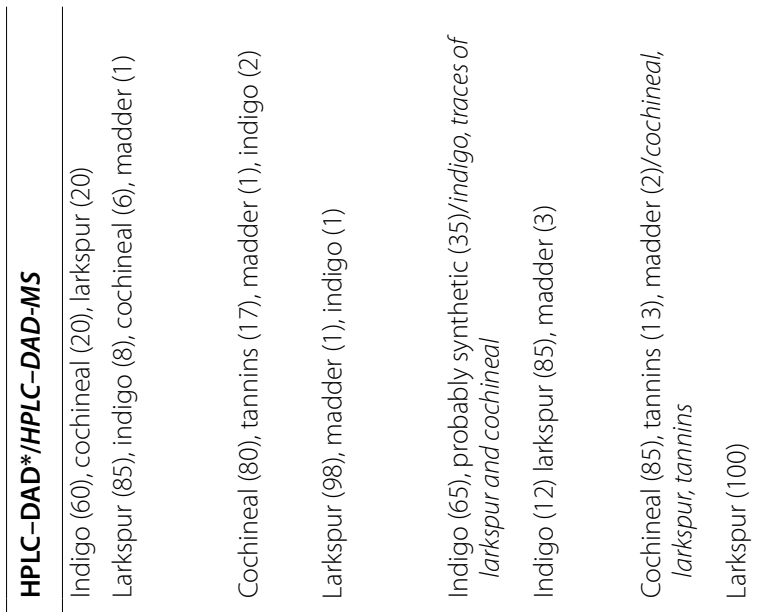
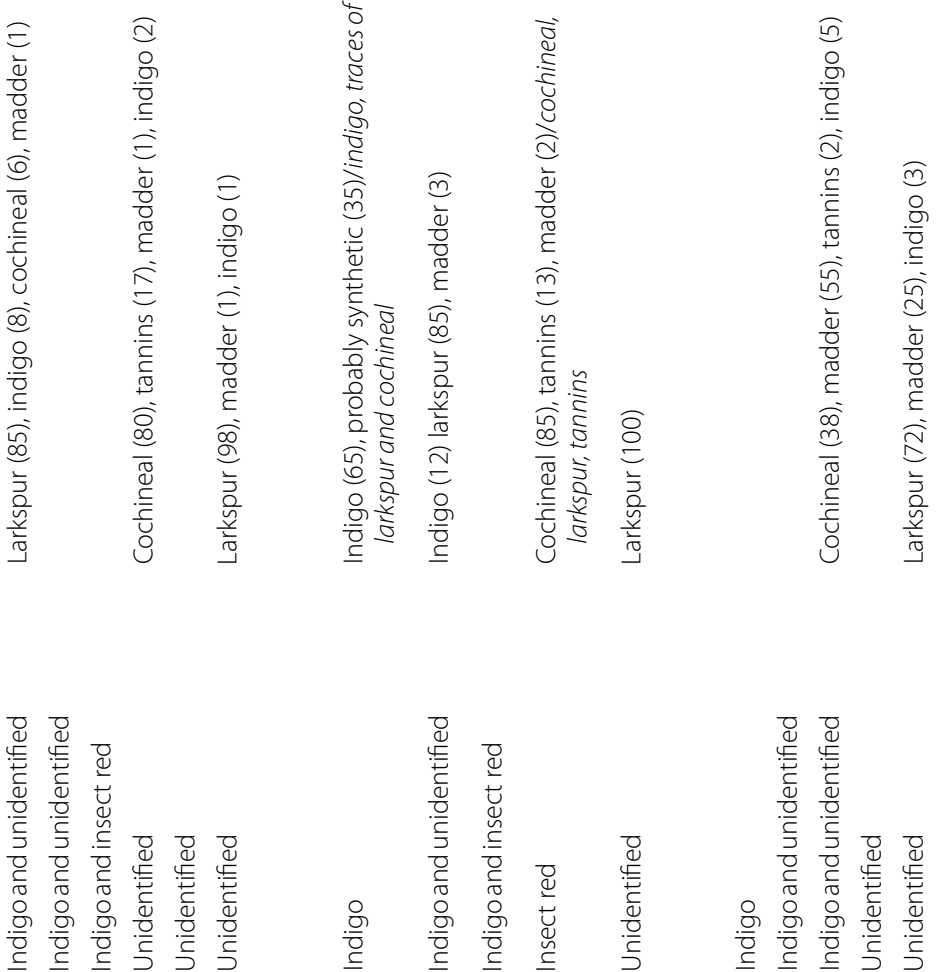

흔

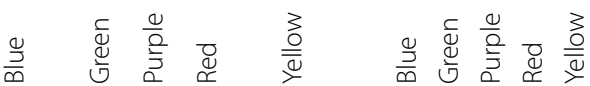
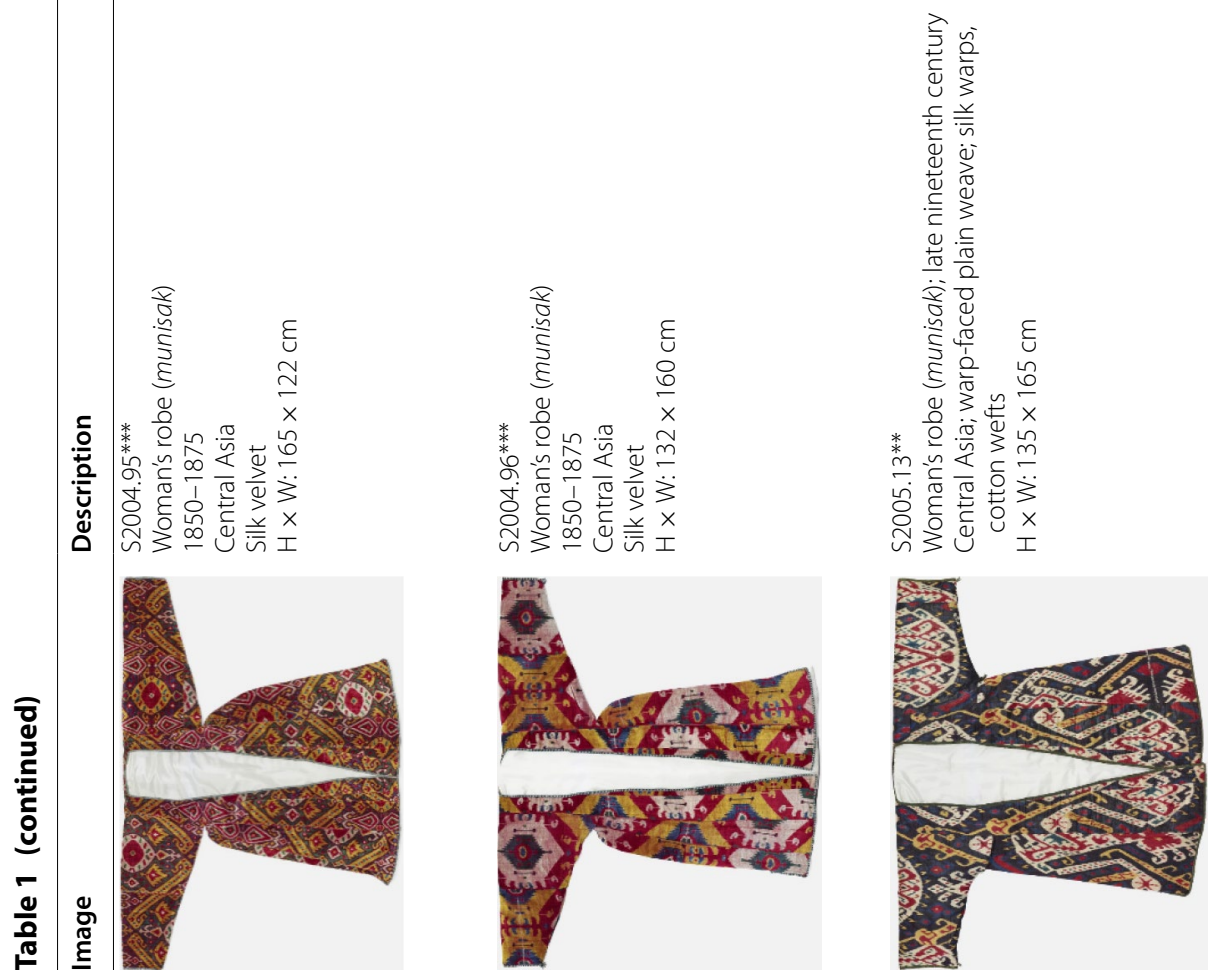


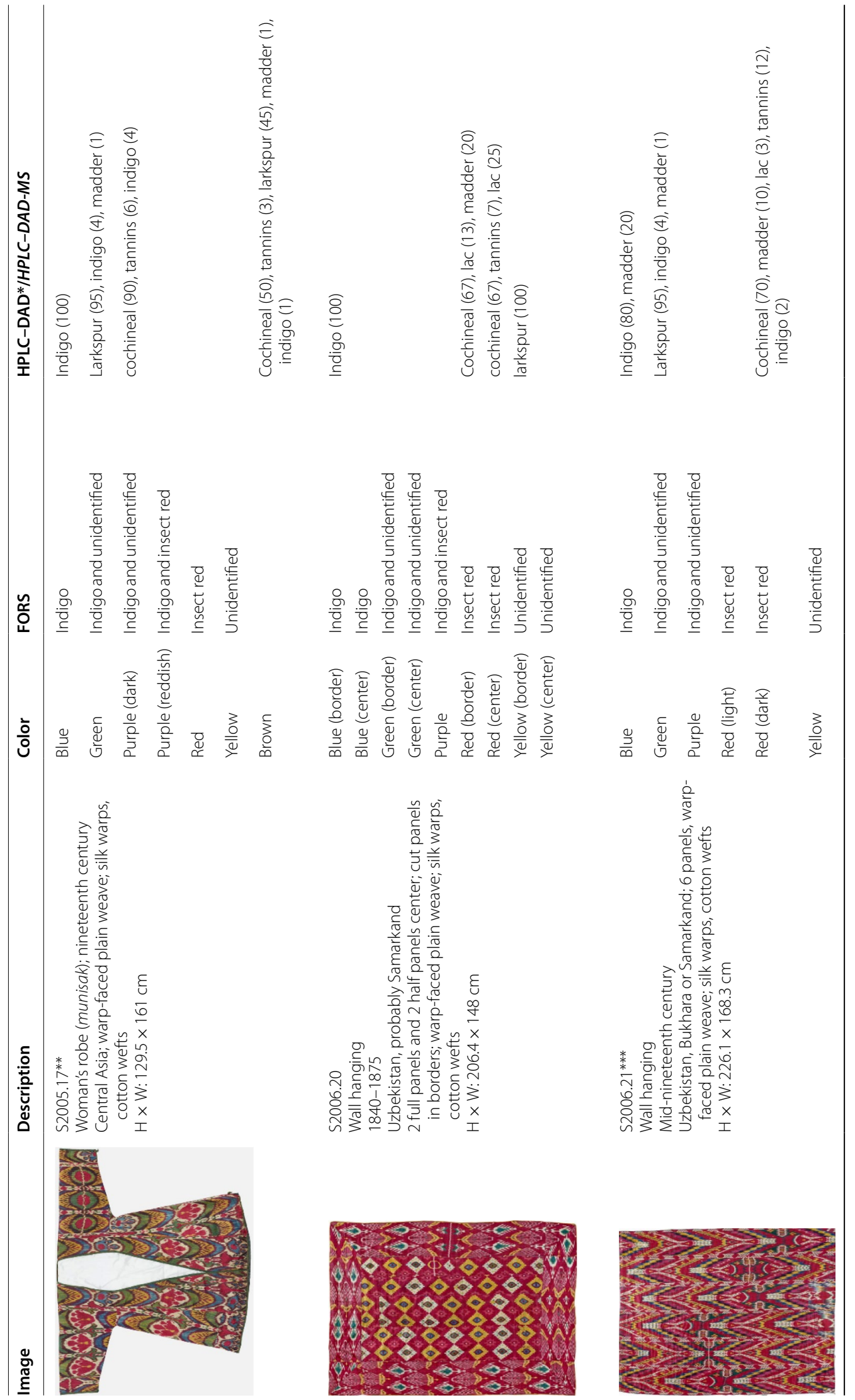




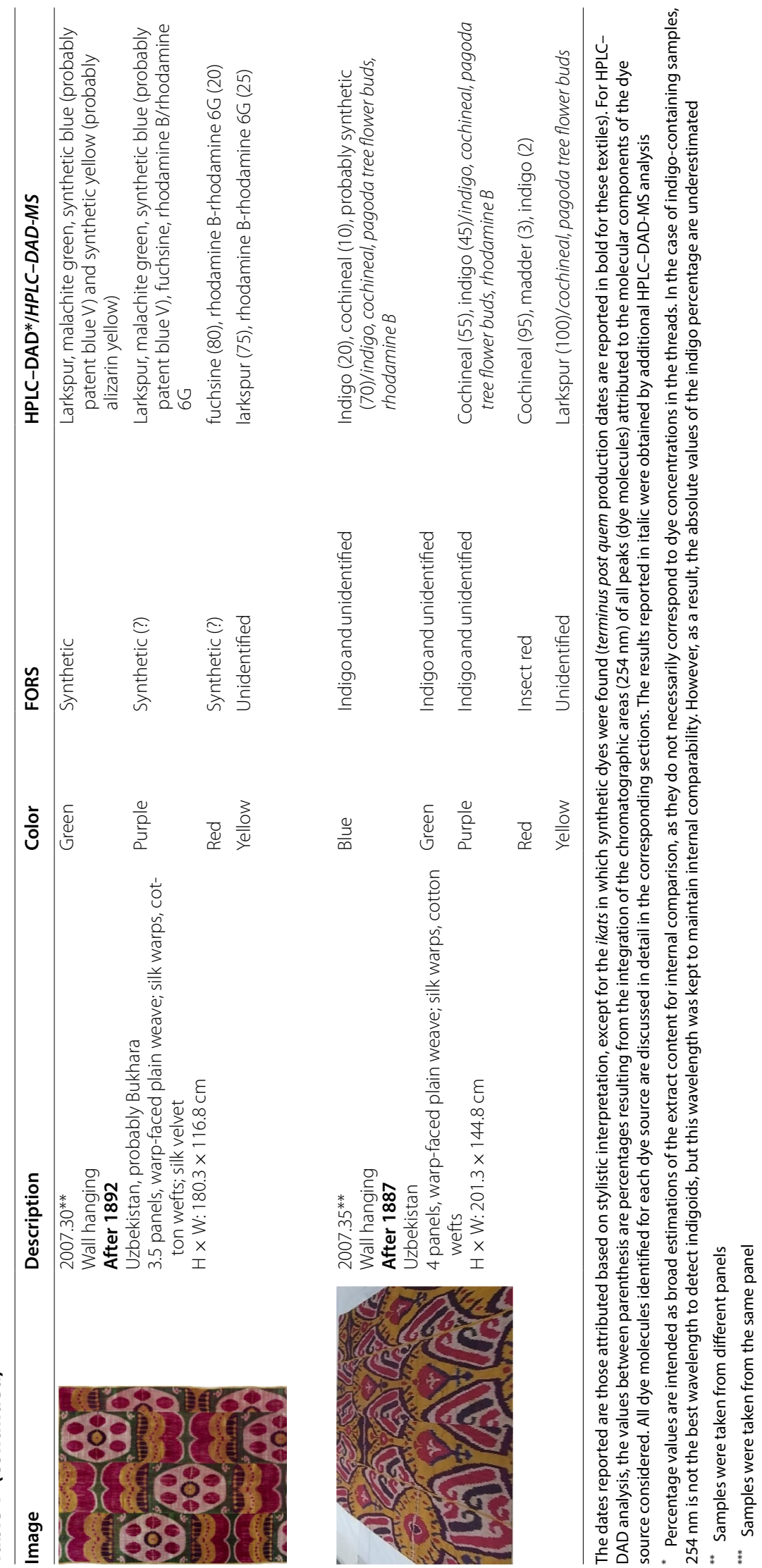




\section{Results}

The analyses performed led to the identification of all sources of natural dyes and most sources of synthetic dyes used to obtain the colors of the $i k a t$ textiles under investigation. The results are summarized in Table 1 and the implications of the findings are discussed in the Discussion section.

\section{Natural red dyes}

The reflectance spectra of most red areas exhibited two small absorption maxima centered at ca. 525 and $565 \mathrm{~nm}$ (Fig. 2a), thus showing the characteristic profile of insectderived red dyes [49]. Although FORS is able to distinguish between plant-derived (the two absorption maxima are at $c a .510$ and $540 \mathrm{~nm}$ ) and insect-derived red dyes, differentiating between the various insect-derived red dyes, in particular kermes, cochineal and lac, is not possible based solely on their reflectance/absorbance features in the UV-Vis range [47].
The application of HPLC revealed a much more complex picture. The main dye was cochineal in all cases, but only in the case of S2004.79 it was found to be the only red dye present, whereas mixtures of cochineal and madder, cochineal and lac, or even cochineal, lac and madder were detected in all the other red areas (Table 1).

Cochineal is a general term used to refer to various insect species, among which American cochineal (Dactylopius coccus), Armenian cochineal or Armenian carmine scale insect (Porphyrophora hamelii) and Polish cochineal or Polish carmine scale insect (Porphyrophora polon$i c a$ ) are historically the most commonly used to produce this red dye. Differentiating the three species is reported to be possible based on the calculation of the chromatographic areas of the various anthraquinones composing the coloring mixture [24, 65]. Specific molecular markers have also been recently identified [14, 37]. In our case, the identification of cochineal was based on the detection of carminic acid $\left(\lambda_{\max }=280,495 \mathrm{~nm} ;[\mathrm{M}-\mathrm{H}]^{-}\right.$at $\mathrm{m} / \mathrm{z}$

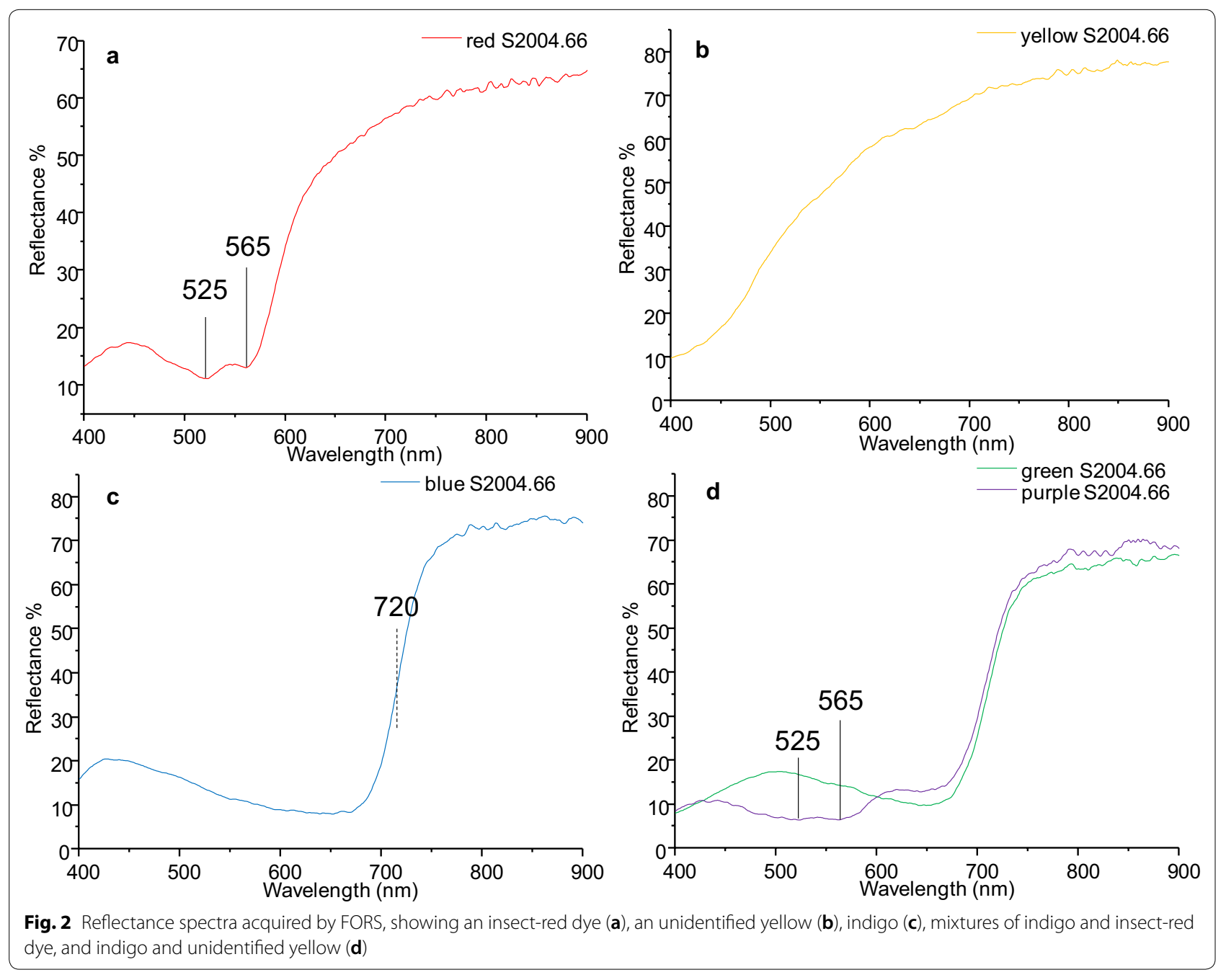


491) present as the main component in all the red samples. In most cases, a series of minor components were detected, which corresponded to the typical compounds present in cochineal and referred to as dcII $\left(\lambda_{\max }=290\right.$, $440 \mathrm{~nm} ;[\mathrm{M}-\mathrm{H}]^{-}$at $\left.m / z 475\right)$, dcIV $\left(\lambda_{\max }=280,495 \mathrm{~nm}\right.$; $[\mathrm{M}-\mathrm{H}]^{-}$at $\left.m / z 491\right)$, dcVII $\left(\lambda_{\max }=280,495 \mathrm{~nm} ;[\mathrm{M}-\mathrm{H}]^{-}\right.$ at $m / z 491)$, kermesic acid $\left(\lambda_{\max }=275,490 \mathrm{~nm} ;[\mathrm{M}-\mathrm{H}]^{-}\right.$ at $m / z 329)$ and flavokermesic acid $\left(\lambda_{\max }=290,435 \mathrm{~nm}\right.$; $[\mathrm{M}-\mathrm{H}]^{-}$at $m / z$ 313) (Fig. 3a). The distribution of these compounds and their percentage areas corresponded to the general values reported for American cochineal $[24,65]$, and this was also confirmed by the presence of specific molecular markers, such as the so-called dc2 ( $C$-glycoside dicarboxylic acid derivative of kermesic acid; $[\mathrm{M}-\mathrm{H}]^{-}$at $m / z 521$ ), dc5 (dehydrocarminic acid; $[\mathrm{M}-\mathrm{H}]^{-}$at $m / z$ 489) and dc9 (carminic acid-2'-(4hydroxybenzoate) or carminic acid- $2^{\prime}$-salicylate; $[\mathrm{M}-\mathrm{H}]^{-}$ at $m / z$ 611) (Fig. 3a) [14]. However, in a few cases the composition and distribution of the minor components did not match with any of the three common sources of

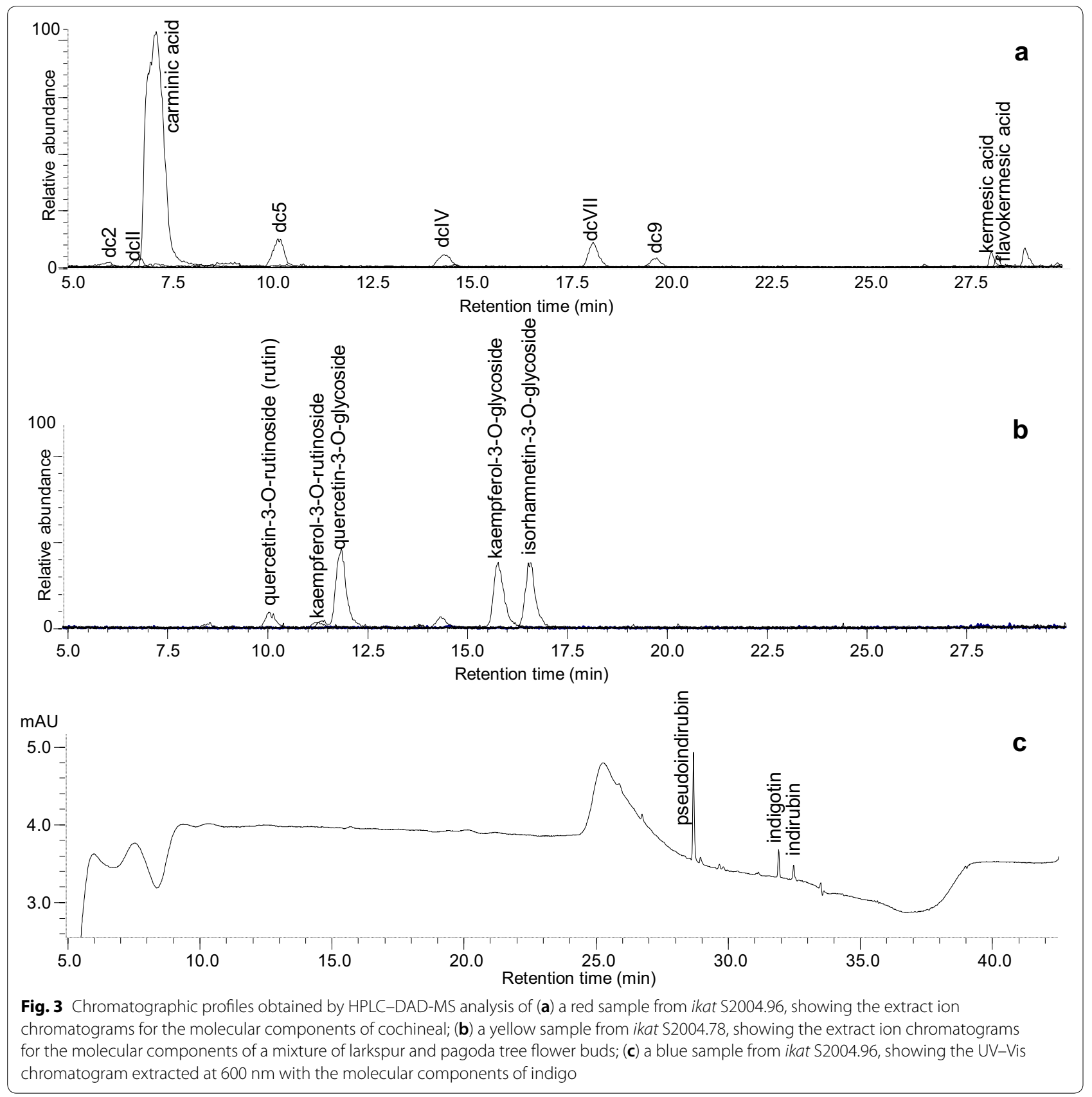


cochineal. This result is in agreement with some previous analyses on Central Asian ikats, in which both American cochineal and a local source of cochineal were proposed [20]. Nevertheless, it has to be underlined that the use of chromatographic areas of minor components may not be precise when it comes to aged historical samples and the composition of the extracts may not be representative of the actual composition of the dyes on the threads, as the extraction procedure may be affected by several unpredictable factors. For these reasons, although American cochineal is likely to be the main source of red dye in most these textiles, as expected after the sixteenth century, we decided to refer to it with the general term cochineal (carminic acid based dye).

Lac dye was identified in 6 textiles (S2004.66, S2004.68, S2004.82, S2004.88, S2006.20 and S2006.21), based on the detection of laccaic acid A $\left(\lambda_{\max }=285,495 \mathrm{~nm} ;[\mathrm{M}-\mathrm{H}]^{-}\right.$ at $m / z 536)$ and laccaic acid $\mathrm{B}\left(\left(\lambda_{\max }=285,495 \mathrm{~nm}\right.\right.$; $[\mathrm{M}-\mathrm{H}]^{-}$at $\left.m / z 495\right)$. Although Kerria lacca is the most common source of lac dye and most likely the one used for these textiles, other insects produce a red dye with very similar composition, e.g. the Paratachardina genus [25]. Therefore, also in this case, we decided to generally refer to this colorant as lac dye. Lac dye was present as a minor component ( $c a .2 \%$ of the chromatographic areas of all red components) in most cases, except for S2004.82 and S2006.20, in which it accounted for ca. 20\% of the chromatographic areas of all red components. In these two samples, laccaic acid $C\left(\lambda_{\max }=285,495 \mathrm{~nm}\right.$; $[\mathrm{M}-\mathrm{H}]^{-}$at $\mathrm{m} / z$ 538) and laccaic acid $\mathrm{E}\left(\lambda_{\max }=285\right.$, $495 \mathrm{~nm} ;[\mathrm{M}-\mathrm{H}]^{-}$at $\left.m / z 494\right)$ were also detected. These are reported as minor components of lac dye [25, 40], and reasonably fell below the detection limit of the technique for all the other samples containing lac dye in very low concentration.

Madder was identified in most red areas of the textiles under investigation (Table 1), based on the presence of alizarin $\left(\lambda_{\max }=255,435 \mathrm{~nm} \text {; [M-H] }\right]^{-}$at $\left.m / z 239\right)$, purpu$\operatorname{rin}\left(\lambda_{\max }=265,485 \mathrm{~nm} ;[\mathrm{M}-\mathrm{H}]^{-}\right.$at $\left.m / z 255\right)$, munjistin $\left(\lambda_{\max }=300,430 \mathrm{~nm} ;[\mathrm{M}-\mathrm{H}]^{-}\right.$at $\left.m / z 283\right)$ and rubiadin $\left(\lambda_{\max }=280,420 \mathrm{~nm} ;[\mathrm{M}-\mathrm{H}]^{-}\right.$at $\mathrm{m} / z$ 253). Similar to lac dye, madder was present as a minor component in some cases (ca. $1-4 \%$ of the chromatographic areas of all red components). However, in the red areas of textiles S2004.68, S2004.72, S2004.76, S2004.82, S2004.83, S2004.91, S2005.13, S2006.20, S2006.21 madder compounds accounted for $c a .5-30 \%$ of the chromatographic areas of all red components. Also in the case of madder, several plant species of the Rubiaceae family are known to produce this red dye. Among them, Rubia tinctorum, $R$. cordifolia, $R$. akane and $R$. peregrina are the most common and the most studied, and methods to distinguish them based on their chemical compositions have been proposed $[23,40]$. All the samples containing madder showed a relatively higher amount of alizarin compared to purpurin, except for S2004.91 and S2006.21 in which alizarin and purpurin were present with comparable amounts. Therefore, it appears that the most likely source of madder dye for the majority of the red samples is $R$. tinctorum. However, as explained in the case of cochineal, there is a high number of factors that can affect the final dyestuff composition observed in a chromatographic analysis, including the natural variability in the chemical composition of the madder root, the dye extraction and preparation procedures, the effects of ageing and the analytical protocol adopted. Although distinctions can generally be made for non-aged reference materials $[23,40]$, the unequivocal identification of the precise botanical source used to prepare the madder dye is not always straightforward when it comes to historical samples. For these reasons, even if $R$. tinctorum is probably the source of this red dye [20], we decided to refer to it with the general term madder.

In addition to red dyes, most red samples contained a source of tannins, as highlighted by the detection of ellagic acid $\left(\lambda_{\max }=368 \mathrm{~nm} ;[\mathrm{M}-\mathrm{H}]^{-}\right.$at $m / z$ 301). Ellagic acid is a common breakdown product of hydrolysable tannins and does not enable the specific source of tannins to be distinguished. During dyeing, tannins can be used to weight silk, as vegetable mordant, or to adjust the shade of the color $[66,67]$. Ellagic acid was detected in very variable relative amounts (ca. 1-30\%) always in combination with red dyes, and not in yellow, blue or green samples, which suggests the use of tannins to adjust the depth of the red color. A certain correspondence was in fact found between darker shades of red, including purple, and higher amounts of tannins.

\section{Natural yellow dyes}

The FORS spectra obtained from most yellow areas did not show any particular feature useful for the non-invasive identification of the yellow dyes (Fig. 2b). It is, in fact, known that only a few yellow dyes (mostly carotenoids) produce distinctive electronic spectra, whereas in all other cases FORS is not suitable for any differentiation $[52,53,68]$.

By contrast, HPLC analysis enabled the botanical sources of these yellow dyes to be identified. In the vast majority of the cases, larkspur (Delphinium semibarbatum) was identified based on the presence of kaempferol-3-O-glycoside $\left(\lambda_{\max }=348 \mathrm{~nm} ;[\mathrm{M}-\mathrm{H}]^{-}\right.$at $m / z$ 447), quercetin-3-O-glycoside $\left(\lambda_{\max }=352 \mathrm{~nm}\right.$; $[\mathrm{M}-\mathrm{H}]^{-}$at $\left.m / z 463\right)$ and isorhamnetin-3-O-glycosides $\left(\lambda_{\max }=356 \mathrm{~nm} ;[\mathrm{M}-\mathrm{H}]^{-}\right.$at $m / z 477$ ) (Fig. 3b) [26, 38]. In addition to the larkspur components, the yellow samples of S2004.66, S2004.78, S2004.80, S2004.90, S2004.92 
and 2007.35 also contained quercetin-3-O-rutinoside (rutin; $\lambda_{\max }=354 \mathrm{~nm} ;[\mathrm{M}-\mathrm{H}]^{-}$at $m / z 609$ ) and kaempferol 3-O-rutinoside $\left(\lambda_{\max }=352 \mathrm{~nm} ;[\mathrm{M}-\mathrm{H}]^{-}\right.$at $\mathrm{m} / z$ 593), which are molecular markers for the use of pagoda tree flower buds (Sophora japonica) [32, 40] (Fig. 3b). These sources of yellow dyes are in agreement with previous analyses [19]. However, an additional yellow dye was identified in one sample from an orange area of S2004.78. In addition to rutin, this sample contained quercetin-3-O-glucuronide $\left(\lambda_{\max }=354 \mathrm{~nm} ;[\mathrm{M}-\mathrm{H}]^{-}\right.$at $m / z$ 477). This molecular combination is reported for grape vine leaves (Vitis vinifera), a yellow dye that has been traditionally used, at least on a small scale, in Iran and Turkey [26].

\section{Natural blue dyes}

The reflectance spectra of most blue areas showed the characteristic steep inflection point of indigo, which occurs at ca. $720 \mathrm{~nm}$ [47] (Fig. 2c). Indigo is produced by several plants, including Indian indigo (Indigofera tinctoria), woad (Isatis tinctoria), Chinese indigo (Polygonum tinctorium) and Strobilanthes cusia among many others. However, all the indigo-producing plants yield the same mixture of colorant molecules and therefore cannot be chemically distinguished. Among these molecules, isatin $\left(\lambda_{\max }=420 \mathrm{~nm} ;[\mathrm{M}+\mathrm{H}]^{+}\right.$at $\left.m / z 148\right)$, indigotin $\left(\lambda_{\max }=620 \mathrm{~nm} ;[\mathrm{M}+\mathrm{H}]^{+}\right.$at $\left.m / z 263\right)$, indirubin $\left(\lambda_{\max }=550 \mathrm{~nm} ;[\mathrm{M}+\mathrm{H}]^{+}\right.$at $\left.m / z 263\right)$, pseudoindirubin $\left(\lambda_{\max }=440,550 \mathrm{~nm} ;[\mathrm{M}-\mathrm{H}]^{-}\right.$at $\left.m / z 500\right)$ and a few other not fully characterized indigoids were detected in all blue (and blue-containing) samples by HPLC analysis (Fig. 3c). Pseudoindirubin has been proposed as a hypothetical marker for woad [62]. However, other indigo-producing plants, although not typically Asian, contain this molecule, and an ultimate confirmation of the indigo source is therefore not obtainable [62]. Nevertheless, it is reported that indigo was mostly imported from China to Central Asia [9].

\section{Natural purple, green and orange colors}

All the mixed colors were composed of mixtures of the red, yellow and blue dyes identified and discussed in the previous sections. For natural green and purple colors, the identification of indigo was obtained by FORS (Fig. 2d) and confirmed by HPLC analysis. When both pure and mixed colors were present on the same textile, the red and yellow dyes mixed with indigo were the same that were used for the pure red and yellow areas, suggesting that red and yellow colors were applied from the same dye bath. This is in agreement with the description of the $i k a t$ dyeing process, in which blue is applied as the last color, both on undyed areas and overlaid on yellow and red areas to obtain green and purple shades respectively $[1,9]$. This order of dye application is only possible using the traditional method of indigo dyeing, which is performed at relatively low temperature $\left(50{ }^{\circ} \mathrm{C}\right.$ max) and mild alkaline conditions [1, 69]. In modern practice, the indigo vat is often created using chemicals such as sodium dithionite and sodium/potassium sulfate/ carbonate, which raise the $\mathrm{pH}$ to approximately 12 and higher temperature is required $[28,70]$. In these conditions, previously applied red and yellow dyes can be easily removed, therefore the order of over-dyeing implies the use of indigo first [70]. The order of application would be an interesting area of further investigation and a possible tool to distinguish indigo dyeing carried out using the natural or chemical process.

\section{Synthetic dyes}

The possible presence of synthetic dyes was suspected based on the reflectance spectra obtained for certain areas. In particular, the green and some of the blue areas of S2004.79, S2004.82, S2004.85, S2004.89 and S2007.30 produced reflectance spectra that easily enabled the presence of indigo to be excluded. A maximum absorption between 610 and $630 \mathrm{~nm}$ was observed (Fig. $4 \mathrm{a}-\mathrm{c}$ ) and this is reported to be typical of several green and blue triarylmethine dyes [71]. The reflectance spectra obtained for the green areas of S2004.90 revealed a possible mixture of indigo and synthetic dyes, as both an inflection point at $720 \mathrm{~nm}$ and a maximum absorption at $580 \mathrm{~nm}$ were observed (Fig. 4d). Some purple and red areas of the same textiles also produced reflectance spectra not corresponding to any natural dye. In these cases, it was more difficult to attribute the spectra to a specific class of synthetic dyes (Fig. 4f), except for the red/purple color of S2004.89, for which the maximum absorbance around $570 \mathrm{~nm}$ suggested the possible presence of a triarylmethine violet (Fig. 4e).

HPLC-DAD-MS analysis revealed again a more complex picture. In the green areas of the textiles S2004.79, S2004.82, S2004.85, S2004.89 and S2007.30, diamond green $\mathrm{B}$, also referred to as malachite green or basic green 4 (C.I. 42000), was identified based on the presence of its main component $\left(\lambda_{\max }=622 \mathrm{~nm} ;[\mathrm{M}+\mathrm{H}]^{+}\right.$ at $m / z$ 329) and a series of mono-demethylated $\left(\lambda_{\max }=608 \mathrm{~nm} ;[\mathrm{M}+\mathrm{H}]^{+}\right.$at $\left.m / z 315\right)$, bis-demethylated $\left(\lambda_{\max }=594 \mathrm{~nm} ;[\mathrm{M}+\mathrm{H}]^{+}\right.$at $m / z$ 301) and tri-demethylated $\left(\lambda_{\max }=580 \mathrm{~nm} ;[\mathrm{M}+\mathrm{H}]^{+}\right.$at $\mathrm{m} / z$ 287) derivatives (Fig. 5), in agreement with literature data [38, 63, 64]. Several isomers were detected, corresponding to different demethylated positions.

The red area of S2004.84 and the red and purple areas of S2007.30 were found to contain fuchsine (basic violet 14, C.I. 42510) and the identification was based on the presence of three compounds, respectively corresponding 

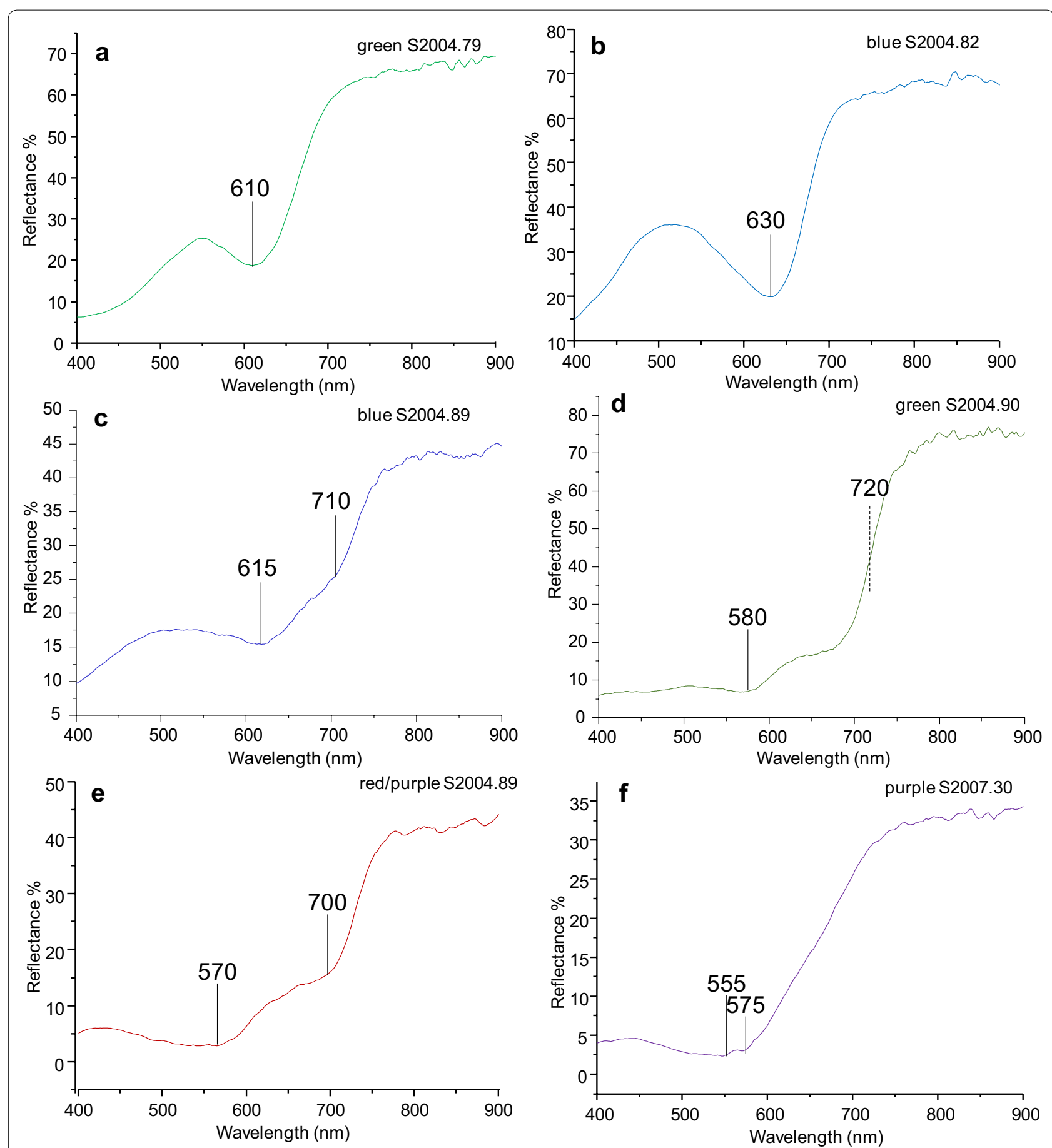

Fig. 4 Reflectance spectra acquired by FORS, showing the possible presence of (a) a triarylmethine green dye, (b, $\mathbf{c})$ a triarylmethine blue dye, (d) a mixture of indigo and an unidentified green dye, (e) a triarylmethine purple dye, (f) an unidentified purple dye

to the fuchsine molecule, also referred to as rosaniline or Magenta I, $\left(\lambda_{\max }=546 \mathrm{~nm} ;[\mathrm{M}+\mathrm{H}]^{+}\right.$at $\left.m / z 302\right)$ and the homologues with one additional methyl group (Magenta II; $\lambda_{\max }=548 \mathrm{~nm} ;[\mathrm{M}+\mathrm{H}]^{+}$at $\left.m / z 316\right)$ and two additional methyl groups on the aromatic rings (Magenta
III, $\lambda_{\max }=550 \mathrm{~nm} ;[\mathrm{M}+\mathrm{H}]^{+}$at $m / z 330$ ) (Fig. 6), also in agreement with published data $[38,44,63,64]$.

Methyl violet (basic violet 1, C.I. 42535), was identified in the purple and red areas of S2004.89. A complex chromatographic profile was obtained, showing 

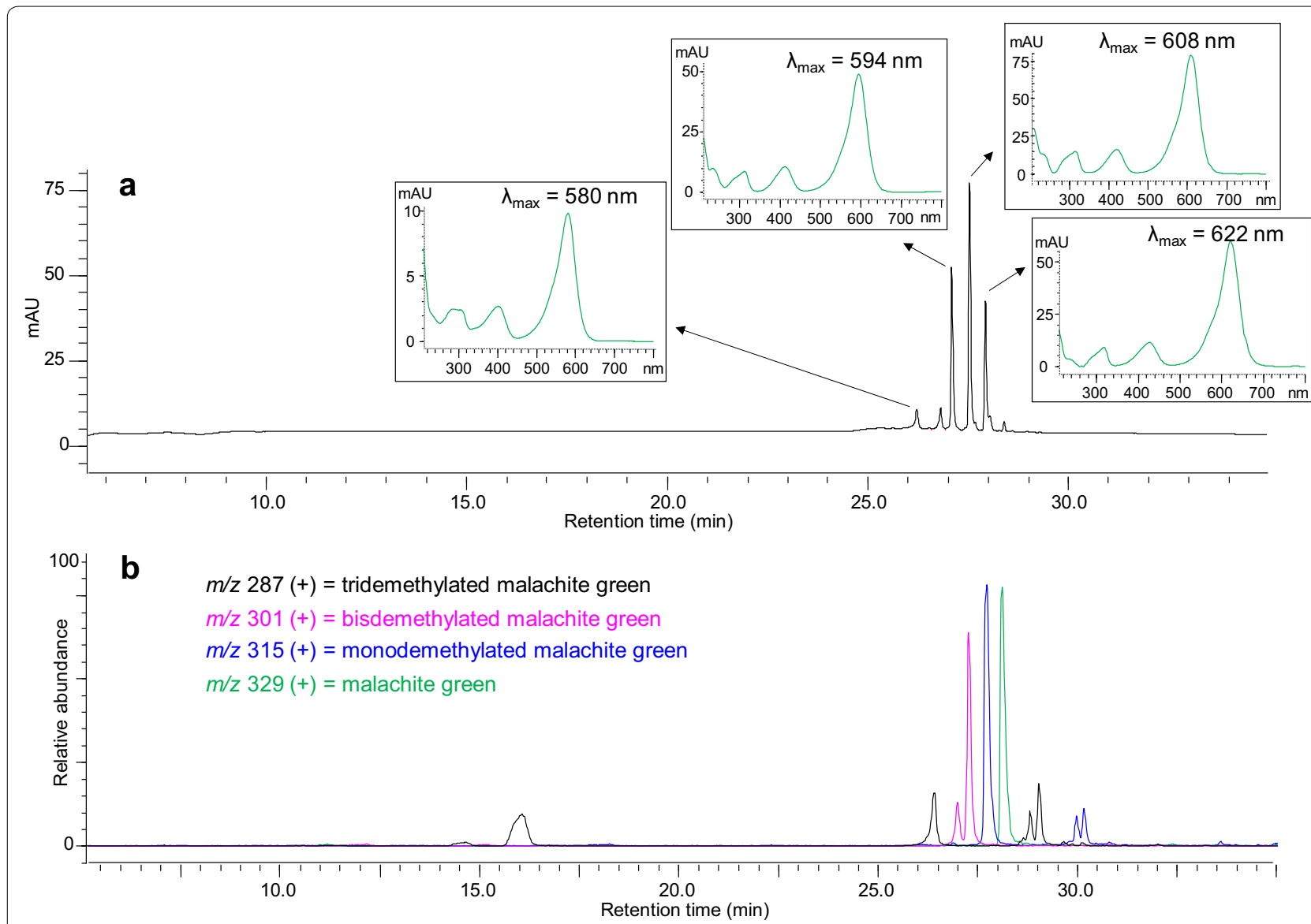

Fig. 5 Chromatographic profiles obtained by HPLC-DAD-MS analysis of a green sample from the ikat textile S2004.85: (a) UV-Vis chromatogram extracted at $600 \mathrm{~nm}$ (inserts show the UV-Vis absorbance spectra of the main compounds); (b) extract ion chromatograms obtained by using the $\mathrm{m} / \mathrm{z}$ values corresponding to the molecular ions $[\mathrm{M}+\mathrm{H}]^{+}$of malachite green components

the same compounds discussed for fuchsine and additional higher homologues of pararosaniline, containing three $\left(\lambda_{\max }=568 \mathrm{~nm} ;[\mathrm{M}+\mathrm{H}]^{+}\right.$at $\left.m / z 330\right)$, four $\left(\lambda_{\max }=576 \mathrm{~nm} ;[\mathrm{M}+\mathrm{H}]^{+}\right.$at $\left.m / z 344\right)$, five $\left(\lambda_{\max }=583 \mathrm{~nm}\right.$; $[\mathrm{M}+\mathrm{H}]^{+}$at $\left.m / z 358\right)$ and six $\left(\lambda_{\max }=588 \mathrm{~nm} ;[\mathrm{M}+\mathrm{H}]^{+}\right.$ at $m / z$ 372) N-methyl groups. Additionally, at least two isomers were detected for the compounds with three, four and five N-methyl groups (Fig. 7). These observations were again in agreement with previous works on the characterization of methyl violet [44, 63], although the lack of tandem mass spectrometry detection did not allow us to precisely assign the various isomers.

The red and green areas of S2004.81, the purple, red and yellow areas of S2007.30 and the purple areas of S2007.35 contained rhodamine B (basic violet 10, C.I. 45170). In the case of textiles S2004.81 and S2007.35, two compounds were detected and identified as rhodamine $\mathrm{B}\left(\lambda_{\max }=558 \mathrm{~nm} ;[\mathrm{M}+\mathrm{H}]^{+}\right.$at $\left.m / z 443\right)$ and the molecule corresponding to the loss of one N-ethyl group $\left(\lambda_{\max }=544 \mathrm{~nm} ;[\mathrm{M}+\mathrm{H}]^{+}\right.$at $m / z$ 415) (Fig. 8).
Rhodamine $\mathrm{B}$ is known to easily photo-degrade and the loss of N-ethyl groups is reported [72]. In the case of S2007.30, in addition to these two compounds, twothree additional peaks were detected with very similar UV-Vis absorption spectra to the ones of rhodamine B, but slightly lower $\lambda_{\max }(c a .530 \mathrm{~nm})$, which matched with the possible presence of rhodamine 6G (basic red 1, C.I. 45160) [64] or additional photo-oxidation products of rhodamine B [72]. Although the retention times closely matched with the compounds present in a reference of rhodamine $\mathrm{G}$, it was not possible to confirm the masses of these compounds by HPLC-DAD-MS, therefore the identification of rhodamine $6 \mathrm{G}$ remains tentative.

In a few other cases, some molecules were detected and possibly related to the presence of synthetic dyes, but a full identification was not possible. In a blue sample from S2004.79, in addition to indigoids, one molecule was detected, whose UV-Vis spectrum $\left(\lambda_{\max }=444 \mathrm{~nm}\right)$ and retention time were similar to (but not perfectly matched) the reference of the azo dye orange IV (acid orange 5, C.I. 


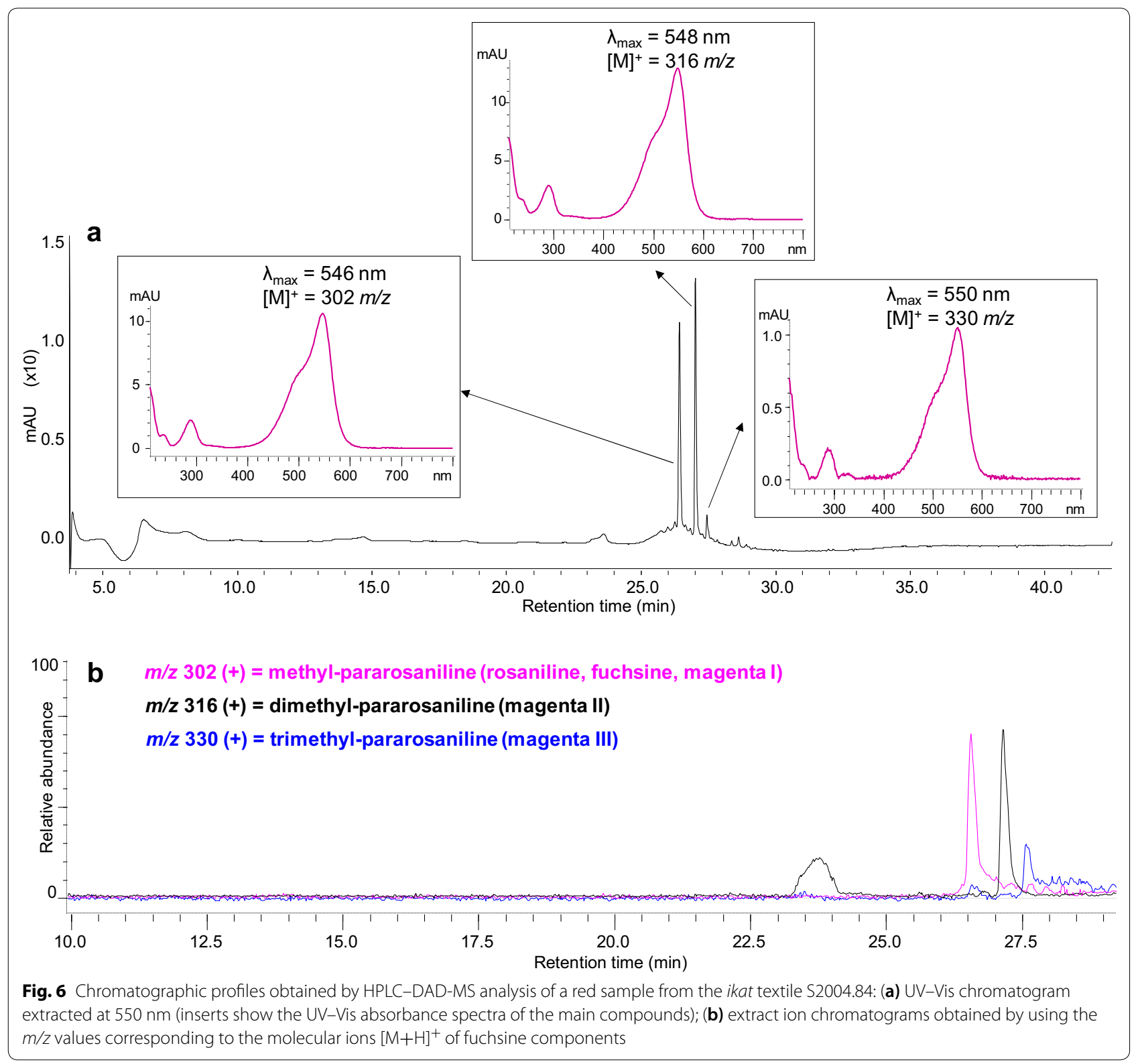

13080) $[63,64]$. The mass of the pseudomolecular ion or any other ion related to the molecule were not detected. In a purple-green sample from S2004.84, in addition to the molecular components of larkspur, cochineal and indigo, four molecules were detected with low relative abundance. The obtained UV-Vis spectra were not of high quality due to the low concentrations, but for two of the molecules a similarity with the UV-Vis spectra of orange I (acid orange 20, C.I. 14600) $\left(\lambda_{\max }=480 \mathrm{~nm}\right)$ and orange II (acid orange 7, C.I. 15510) $\left(\lambda_{\max }=488\right) \mathrm{nm}$ was respectively observed $[63,64]$. Nevertheless, the masses of none of these molecules were detected by MS, therefore this possible mixture of azo dyes is only tentatively identified. Finally, in a blue-green sample from S2004.82 and in a green sample from 2007.30, in addition to malachite green, four additional molecules were detected. Three of these molecules were present as a triplet and the UV-Vis spectra $\left(\lambda_{\max }=593,607,620 \mathrm{~nm}\right.$ respectively) and retention times matched with the compounds present in the triarylmethine dye patent blue $\mathrm{V}$ (acid blue 3, C.I. 42051) $[63$, 64]. The fourth molecule showed a UV spectrum $\left(\lambda_{\max }=352 \mathrm{~nm}\right)$ and a retention time matching alizarin yellow GG (mordant yellow 1, C.I. 14025). As it was not possible to repeat the analysis with HPLC-DADMS to confirm the mass of these molecules, these identifications also remain tentative. 


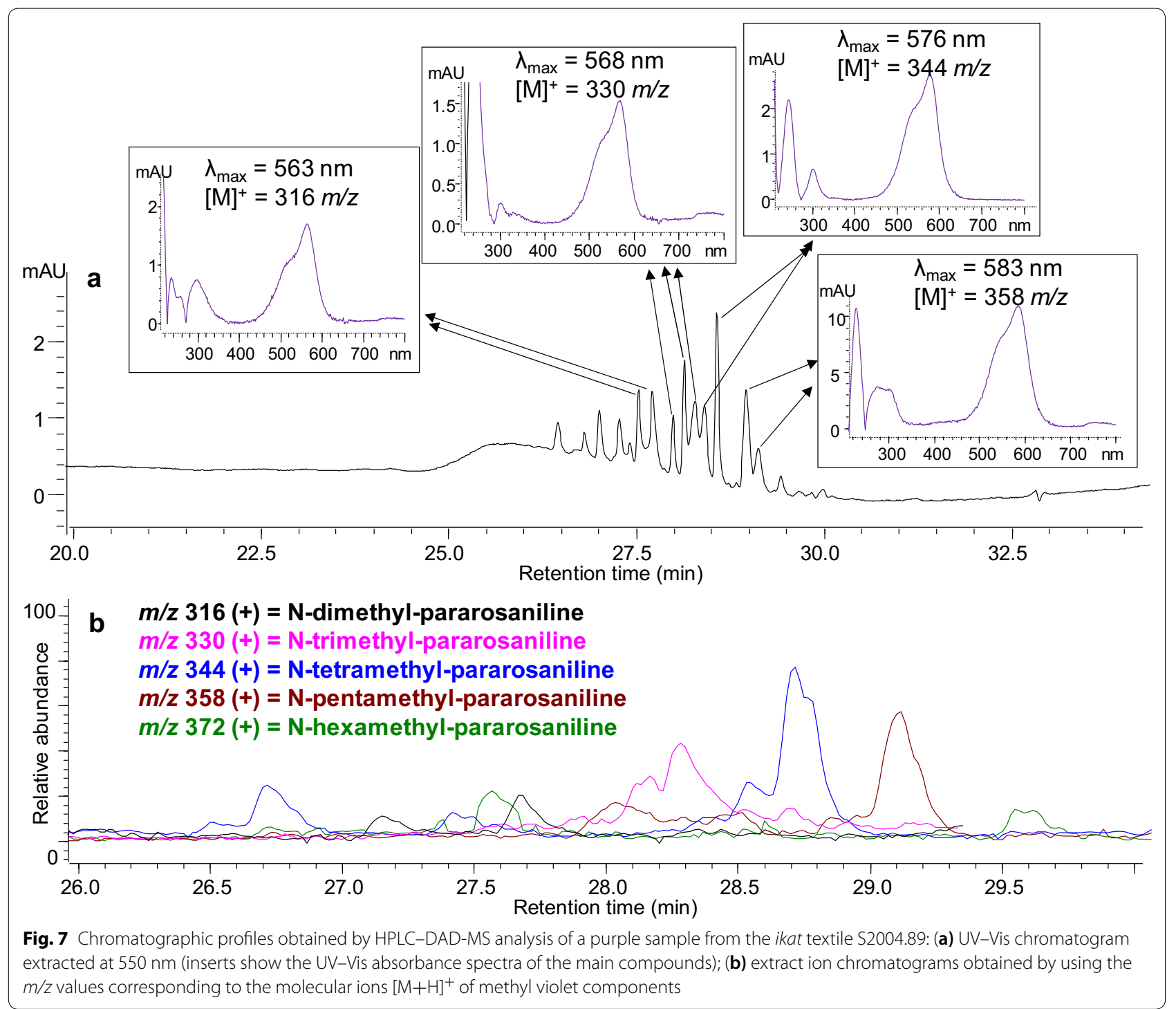

\section{Discussion}

It appeared from the results of this research that the natural sources of dyes were mostly in agreement with local dyes used in Central Asia in the nineteenth century $[1,20,38]$. The only exception is represented by the yellow dye extracted from grape vine leaves (Vitis vinifera), which was identified in one sample from textile S2004.78. This $i k a t$ is the only known example of an uncut complete loom length textile, and it is a velvet, showing some orange pile warps as a repeating pattern. These warps are the ones containing the grape vine leaves dye, which is reported to be used in Iran and Turkey [26]. Considering that Iran has an ikat tradition, an Iranian influence is hypothesized for this textile. However, the design confidently places the textile as a Central Asian piece (Pers. Comm., Massumeh Farhad and Sumru Belger Krody, 2020), therefore it is more likely that the dye (or dyers) had come from the Mediterranean area rather than the textile being produced in Iran. Interestingly, textile S2004.85, which is attributed to Iranian manufacture, did not show the presence of this dye.

Additionally, S2004.89 and S2004.92 were previously investigated and the results of the dye analysis were presented in Wouters' Appendix II in "Ikat: Silks of Central Asia, The Guido Goldman Collection" as numbers 369 and 309, respectively [20]. Our results are in good agreement with these previous analyses and we were able to report the identification of the synthetic dye (methyl violet) previously suspected in S2004.89 (Table 1). No other textiles were analyzed in both studies.

Red colors were very rarely produced using only one dye. Cochineal appears to be the main red dye, but 


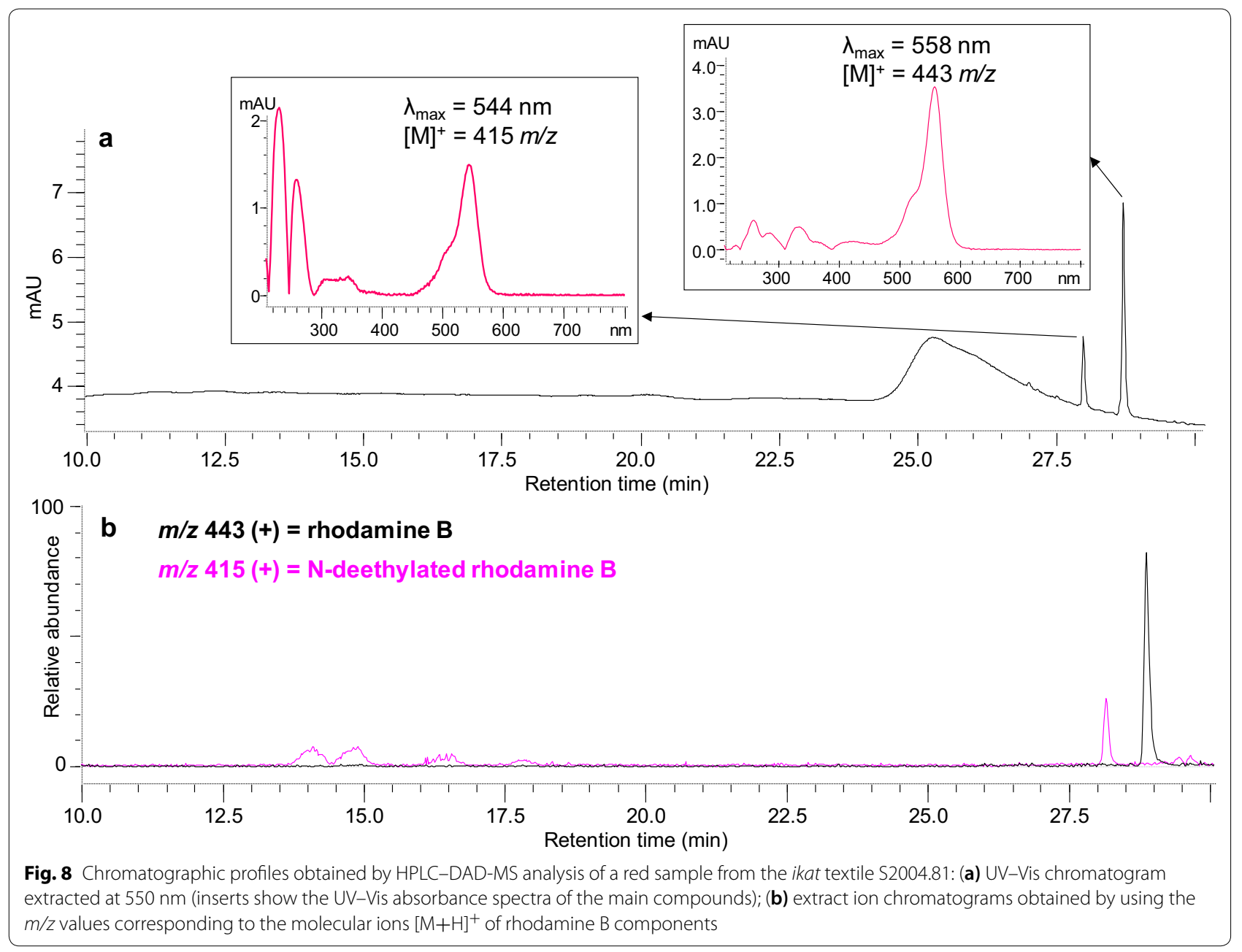

madder and lac dye were often added as well. Madder is actually mentioned as the original red dye in the region [1], lac was mostly imported from India or China, and cochineal come from America through Europe, thus revealing a dynamic scenario. It was particularly interesting to notice that the textiles containing the highest percentage of madder (S2004.83 and S2004.91) are also considered among the oldest ones and are attributed to the first half of the nineteenth century. If this interpretation is correct, the results may point towards a progressive replacement of madder by cochineal during the course of the century. More data are needed to confirm this hypothesis. It is also difficult to establish at which stage of the $i k a t$ production these mixtures were created. It might have been a deliberate choice of the dyers, or such mixtures might have been prepared by merchants and sold to the dyers. In addition, residual dyes from previous dye baths cannot be excluded. Regardless of the ultimate answer, it has to be borne in mind that by the second half of the nineteenth century ikat production was at its highest point and constituted a business, which involved many different professionals and stages of production. However, the economic scenario was not good. Reducing costs by looking for cheaper alternatives must have been a driving force during ikat production.

Out of the $26 i k a t$ textiles analyzed, 9 were found to contain early synthetic dyes. Fuchsine, methyl violet, malachite green and rhodamine B were synthesized in 1856, 1861, 1877 and 1887 respectively [18]. Among the other synthetic dyes tentatively identified, orange I and orange II were synthesized in 1876, alizarin yellow GG in 1887, patent blue $\mathrm{V}$ in 1888, and rhodamine 6G in 1892 [18]. The ikats S2004.79 and S2004.85 were attributed to 1850-1900, but the presence of malachite green moves the possible production date of these textiles to at least the last quarter of the nineteenth century. For S2004.81 and S2007.35, originally attributed to 1825-1875 and mid-nineteenth century respectively, the presence of rhodamine B significantly moves the possible production date to after 1887. S2004.89 and S2007.30 were attributed 
to $1850-1875$, but for the former, the presence of both methyl violet and malachite green moves the possible production date to after 1877 , whereas for the latter, the detection of several synthetic dyes, including rhodamine B (and possibly rhodamine 6G), moves the possible production date to at least the end of the nineteenth century. S2004.82 and S2004.84 and S2004.90 were already attributed to 1875-1900 and the presence of synthetic dyes confirms a relatively late production of these textiles. The presence of the tentatively identified dyes does not affect the refined dating of these textiles and additional analyses are foreseen, possibly using HRMS and/or MS/MS detectors, in order to confirm the identification by considering additional samples from these textiles (such as the blue from S2004.89 and the green from S2004.90) and other $i k a t s$ in the collection. It is also worth underlining that, as some time inevitably passed between the commercialization of these synthetic dyes in Europe and their export and use in Central Asia, some of the ikats containing synthetic dyes may have been produced at the beginning of the twentieth century.

The early synthetic dyes detected are in agreement with other studies that scientifically confirm the introduction of the same classes of synthetic dyes to Central Asia [38] and China [36] by the late nineteenth century-early twentieth century. It also appears that green, purple and blue synthetic dyes were most commonly used during this transition phase in agreement with these colors being more difficult to obtain using natural dyes, whereas red and yellow dyes seem to remain natural for a longer time, with the exception of some pink shades obtained with rhodamine and fuchsine.

Additionally, it was interesting to notice that in no case the textiles were entirely dyed with synthetic dyes. Mixtures of natural and synthetic dyes were used not just in the same textile, but even to produce a single color, and this represents a rare window into the transitional and experimental phase that dyers experienced in the late nineteenth century. Guido Goldman's intention to only buy naturally-dyed ikats is likely to have been shared by many other early buyers, who did not appreciate the flashy and unnatural colors produced by synthetic dyes. Dyers might have initially tried to adjust the color shades by mixing natural and cheaper synthetic dyes to mimic natural dyes, and, as synthetic dyes were also already known not to be particularly lightfast, mixing a percentage of natural dyes would have made the color last longer. The use of mixtures of natural and synthetic dyes for labor or cost savings follows what we assume to be an established practice in the production of ikats: the red dye cochineal, found in all the ikats analyzed, while a natural dye, was identified as imported American cochineal, supporting a history of the use of imported dyes and, similarly to the synthetics, was used as a mixture with other red dyes.

A final contextualization of the results was attempted in the light of the common stylistic assumption that more complex designs with more colors are dated earlier than simpler, larger and more graphic ones. This assumption has its roots into the worsening of the economic situation towards the end of the nineteenth century. While the demand for $i k a t$ production was increasing, dyers and weavers had less means and time to fulfill such demand. The reduction of the complexity and labor intensity of the ikat production was a natural outcome and translated into larger, more stylized designs obtainable by binding the threads less frequently. Among the textiles under investigation, some complex and intricate designs are present, e.g. S2004.75, S2004.76, S2004.83, S2004.91, 2006.20, 2006.21, and the four robes (Table 1). In none of these textiles were synthetic dyes detected, which does not confirm a precise production date, but partially supports a possible early one. On the other hand, the textiles containing synthetic dyes all exhibit relatively simple designs. However, among the naturally-dyed textiles, some relatively simple motifs are present as well, e.g. S2004.66, S2004.78, S2004.88, S2004.92, etc. Therefore, although a good correspondence was found between simpler motifs possibly being produced later, further investigation would be useful to expand on this topic.

\section{Conclusions}

Dye analysis was carried out on 26 Central Asian ikat textiles from the Arthur M. Sackler Gallery collection mostly attributed to the second half of the nineteenth century.

The study represents a valuable example of the importance of combining non-invasive and invasive analysis. In fact, although FORS gave an overview of the presence and distribution of some dyes, including indigo, insect-based red dyes and synthetic dyes, HPLC analysis on selected samples revealed complex mixtures of dyes, partially as a result of the $i k a t$ dyeing process, which were not highlighted non-invasively. DAD detection was suitable to identify most sources of natural dyes, but MS proved fundamental to confirm their presence and further identify some of the synthetic dyes.

Three main sources of red natural dyes and three main sources of yellow natural dyes were identified, namely for reds: cochineal, madder, lac, and for yellows: larkspur, pagoda tree flower buds and grape vine leaves, with cochineal and larkspur being the most common ones. Indigo was used for all the natural blue shades, and tannins were used to adjust the color of 
the red shades. These dyes fit with the sources of color reported to be available and in use in Central Asia in the nineteenth century. The identification of early synthetic dyes, namely fuchsine, methyl violet, malachite green and rhodamine $\mathrm{B}$, was fundamental to adjust the dating of the 9 textiles in which they were detected. Additional synthetic dyes, including early mono-azo dyes, were tentatively identified and future research will be dedicated to analyze more samples from Central Asian ikats and compare the results. The use of tandem mass spectrometry is also foreseen as an additional tool for a more accurate molecular identification.

In addition to underlining the importance of scientific analysis to support art historical interpretation, this study creates a window on a dynamic dyeing scenario, in which dyers were experimenting and adjusting during a period of economic and technological change.

\begin{abstract}
Abbreviations
FORS: Fiber optic reflectance spectroscopy; HPLC: High pressure liquid chromatography; DAD: Diode array detector; MS: Mass spectrometry; HRMS: High resolution mass spectrometry; C.I.: Color index; UV: Ultraviolet; Vis: Visible; MSI: Multispectral imaging; $\lambda_{\max }$ : Maximum wavelength; $m / z$ : Mass to charge ratio.
\end{abstract}

\section{Acknowledgements}

The authors would like to thank Jan Wouters for providing expertise on dye analysis that was instrumental in getting the project underway; Massumeh Farhad (Chief Curator and The Ebrahimi Family Curator of Persian, Arab, and Turkish Art, Freer Gallery of Art and Arthur M. Sackler Gallery, National Museum of Asian Art, Smithsonian Institution, Washington DC, USA), Sumru Belger Krody (Senior Curator, George Washington University Museum and The Textile Museum, Washington DC, USA) and Mary Ballard (Senior Textile Conservator, Museum Conservation Institute, Smithsonian Institution, Washington DC, USA) for useful discussions; Morgan Meador for her work on the ikats motifs; the Gaddy family for enabling data transfer.

Esther Méthé (formerly George Washington University Museum and The Textile Museum, Washington DC, USA), and Mary Ballard provided reference materials produced at dye analysis workshops conducted by Dr. Helmut Schweppe held at the former Smithsonian Conservation Analytical Laboratory. References of natural dyes were made available by the Getty Conservation Institute from materials produced during their Asian Organic Colorants project (2006-2010, https://www.getty.edu/conservation/our_projects/science/asian /index.html).

This work was supported by the Smithsonian Institution Postdoctoral Fellowship program, which funded Dr. Diego Tamburini's fellowship.

\section{Authors' contributions}

DT was responsible for overall data interpretation and drafting of the article; CM was responsible for acquisition of HPLC-DAD-MS data; EB was responsible for sampling, and acquisition and interpretation of HPLC-DAD data; TK was responsible for acquisition of FORS data; MLC was responsible for supporting lab activities; BM was responsible for conception and design of the study. All authors read and approved the final manuscript.

\section{Funding}

No specific source of funding was used for this research.

\section{Availability of data and materials}

The datasets used and/or analysed during the current study are available from Dr. Blythe McCarthy and Dr. Matthew L. Clarke on reasonable request.

\section{Competing interests}

The authors declare that they have no competing interests.

\section{Author details}

${ }^{1}$ Department of Conservation and Scientific Research, Freer Gallery of Art and Arthur M. Sackler Gallery, National Museum of Asian Art, Smithsonian Institution, 1050 Independence Ave SW, Washington, DC 20560, USA. ${ }^{2}$ Present Address: Department of Scientific Research, Metropolitan Museum of Art, 1000 5th Ave, New York, NY 10028, USA. ${ }^{3}$ Present Address: National Institute of Technology, Fukui College, Geshi-cho, Sabae, Fukui 916-8507, Japan. ${ }^{4}$ Present Address: National Ainu Museum, 2-3-1 Wakakusa-cho, Shiraoicho, Hokkaido, Japan.

Received: 14 July 2020 Accepted: 22 September 2020

Published online: 10 November 2020

\section{References}

1. Fitz Gibbon K, Hale A. Ikat: Silks of Central Asia. The Guido Goldman Collection. London: Lawrence King Publishing; 1997.

2. de Avila B. A Mexican ikat and transatlantic trade. In: Textile Society of America's 15th Biennial Symposium, Savannah. GA, 2016

3. VanStan I. A Peruvian Ikat from Pachacamac. Am Antiq. 1957;23(2):150-9. https://doi.org/10.2307/276438.

4. Buckley CD. Investigating cultural evolution using phylogenetic analysis: the origins and descent of the Southeast Asian tradition of warp Ikat weaving. PLoS ONE. 2012;7(12):e52064. https://doi.org/10.1371/journ al.pone.0052064.

5. Parmal PA (2004) The impact of synthetic dyes on the luxury textiles of Meiji Japan. In: Paper presented at the Textile Society of America 9th Biennial Symposium, Oakland, California, October 7-9

6. Hann MA. Origins of central Asian silk ikats (Origins of central Asian silk ikats). Res J Costume Cult. 2013;21(5):780-91. https://doi.org/10.7741/ rjcc.2013.21.5.780.

7. Clark R. Central Asia Ikats. London: Victoria and Albert Museum; 2007.

8. Rivers VZ (2004) Culture on a platter: politicization of Central Asian Ikat Patterns. In: Paper presented at the Textile Society of America 9th Biennial Symposium, Oakland, California, October 7-9

9. Krody SB. Colors of the oasis: Central Asian ikats. Washington, D.C.: Textile Museum; 2010.

10. Mackie LW (2015) Symbols of power: luxury textiles from Islamic Lands, 7th-21st Century. Cleveland Museum of Art,

11. Barnes R. Dressing for the great game - the robert shaw collection in the Ashmolean Museum. Khil'a. 2005;1:1-13. https://doi.org/10.2143/ kh.1.0.629995.

12. Fitz Gibbon K, Hale A. Ikat: Appendix I_Notes on nineteenth-century dye recipes. Ikat: Silks of Central Asia, The Guido Goldman Collection. London: Lawrence King Publishing; 1997.

13. Jolly A, Vanden Berghe I, Wouters J. Europe or China? Dyestuff analyses as a tool for attributions. In: Kirby J, editor. The diversity of dyes in history and archaeology. London: Archetype Publications; 2017. p. 6-17.

14. Lech K, Witkoś K, Wileńska B, Jarosz M. Identification of unknown colorants in pre-Columbian textiles dyed with American cochineal (Dactylopius coccus Costa) using high-performance liquid chromatography and tandem mass spectrometry. Anal Bioanal Chem. 2015;407(3):855-67. https://doi.org/10.1007/s00216-014-8107-y.

15. Tamburini D, Cartwright CR, Melchiorre Di Crescenzo M, Rayner G. Scientific characterisation of the dyes, pigments, fibres and wood used in the production of barkcloth from Pacific islands. Archaeol Anthropol Sci. 2019;11(7):3121-41. https://doi.org/10.1007/s12520-018-0745-0.

16. Dyer J, Tamburini D, Sotiropoulou S. The identification of lac as a pigment in ancient Greek polychromy - The case of a Hellenistic oinochoe from Canosa di Puglia. Dyes Pigm. 2018;149:122-32. https://doi.org/10.1016/j. dyepig.2017.09.062.

17. Sousa MM, Melo MJ, Parola AJ, Morris PJT, Rzepa HS, Melo JSS. A study in mauve: unveiling Perkin's dye in historic samples. Chemistry. 2008;14(28):8507-13. https://doi.org/10.1002/chem.200800718.

18. van Bommel MR, Berghe IV, Wallert AM, Boitelle R, Wouters J. Highperformance liquid chromatography and non-destructive three-dimensional fluorescence analysis of early synthetic dyes. J Chromatogr A. 2007;1157(1):260-72. https://doi.org/10.1016/j.chroma.2007.05.017. 
19. Welham RD. The early history of the synthetic dye industry. I Soc Dyers Colour. 1963;79(4):146-52. https://doi.org/10.1111/j.1478-4408.1963. tb02544.x.

20. Wouters J. Appendix II—dye analysis of nineteenth-century ikats from Central Asia. Ikat: Silks of Central Asia. London: The Guido Goldman Collection. Lawrence King Publishing; 1997. p. 346-353.

21. Degano I, Ribechini E, Modugno F, Colombini MP. Analytical methods for the characterization of organic dyes in artworks and in historical textiles. Appl Spectrosc Rev. 2009;44(5):363-410. https://doi.org/10.1080/05704 920902937876.

22. Pauk V, Barták P, Lemr K. Characterization of natural organic colorants in historical and art objects by high-performance liquid chromatography. Sep Sci. 2014;37(23):3393-410. https://doi.org/10.1002/jssc.201400650.

23. Mouri C, Laursen R. Identification of anthraquinone markers for distinguishing Rubia species in madder-dyed textiles by HPLC. Microchim Acta. 2012;179(1):105-13. https://doi.org/10.1007/s00604-012-0868-4.

24. Serrano A, van den Doel A, van Bommel M, Hallett J, Joosten I, van den Berg KJ. Investigation of crimson-dyed fibres for a new approach on the characterization of cochineal and kermes dyes in historical textiles. Anal Chim Acta. 2015;897:116-27. https://doi.org/10.1016/j.aca.2015.09.046.

25. Santos R, Hallett J, Oliveira MC, Sousa MM, Sarraguça J, Simmonds MSJ, Nesbitt M. HPLC-DAD-MS analysis of colorant and resinous components of lac-dye: a comparison between Kerria and Paratachardina genera. Dyes Pigm. 2015;118:129-36. https://doi.org/10.1016/j.dyepi g.2015.02.024.

26. Mouri C, Mozaffarian V, Zhang X, Laursen R. Characterization of flavonols in plants used for textile dyeing and the significance of flavonol conjugates. Dyes Pigm. 2014;100:135-41. https://doi.org/10.1016/j.dyepi g.2013.08.025.

27. Mouri C, Laursen R. Identification and partial characterization of C-glycosylflavone markers in Asian plant dyes using liquid chromatography-tandem mass spectrometry. J Chromatogr A. 2011;1218(41):7325-30. https:// doi.org/10.1016/j.chroma.2011.08.048.

28. Wouters J, Grzywacz CM, Claro A. A comparative investigation of hydrolysis methods to analyze natural organic dyes by HPLC-PDA —-nine methods, twelve biological sources, ten dye classes, dyed yarns. Pigments Paints Stud Conserv. 2011;56(3):231-49. https://doi.org/10.1179/20470 $5811 \times 13110713013353$

29. Vanden Berghe I, Gleba M, Mannering U. Towards the identification of dyestuffs in Early Iron Age Scandinavian peat bog textiles. J Archaeol Sci. 2009;36(9):1910-21. https://doi.org/10.1016/j.jas.2009.04.019.

30. Karapanagiotis I, Theologou J, Lakka A, Ozoline A, Panayiotou C. Investigation of the colouring materials of Fustat carpet fragments. Archaeometry. 2011;53(3):587-99. https://doi.org/10.1111/j.1475-4754.2010.00569.x.

31. Wouters J, Grzywacz CM, Claro A. Markers for identification of faded safflower (Carthamus tinctorius L.) colorants by HPLC-PDA-MS - ancient fibres, pigments, paints and cosmetics derived from antique recipes. Stud Conserv. 2010;55(3):186-203. https://doi.org/10.1179/sic.2010.55.3.186.

32. Han J, Wanrooij J, van Bommel M, Quye A. Characterisation of chemical components for identifying historical Chinese textile dyes by ultra high performance liquid chromatography — photodiode array —electrospray ionisation mass spectrometer. J Chromatogr A. 2017;1479:87-96. https:// doi.org/10.1016/j.chroma.2016.11.044.

33. Tamburini $D$, Cartwright $C R$, Pullan M, Vickers H. An investigation of the dye palette in Chinese silk embroidery from Dunhuang (Tang dynasty). Archaeol Anthropol Sci. 2018. https://doi.org/10.1007/s1252 0-017-0592-4

34. Peggie DA, Kirby J, Poulin J, Genuit W, Romanuka J, Wills DF, De Simone A, Hulme AN. Historical mystery solved: a multi-analytical approach to the identification of a key marker for the historical use of brazilwood (Caesalpinia spp.) in paintings and textiles. Anal Methods. 2018;10(6):617-23. https://doi.org/10.1039/c7ay02626a.

35. Degano I, Tognotti P, Kunzelman D, Modugno F. HPLC-DAD and HPLC-ESIQ-ToF characterisation of early 20th century lake and organic pigments from Lefranc archives. Herit Sci. 2017;5(1):7. https://doi.org/10.1186/s4049 4-017-0120-y.

36. Liu J, Zhou Y, Zhao F, Peng Z, Wang S. Identification of early synthetic dyes in historical Chinese textiles of the late nineteenth century by highperformance liquid chromatography coupled with diode array detection and mass spectrometry. Color Technol. 2016;132(2):177-85. https://doi. org/10.1111/cote.12205.
37. Lech K, Jarosz M. Identification of Polish cochineal (Porphyrophora polonica L.) in historical textiles by high-performance liquid chromatography coupled with spectrophotometric and tandem mass spectrometric detection. Anal Bioanal Chem. 2016;408(12):3349-58. https://doi. org/10.1007/s00216-016-9408-0.

38. Chen VJ, Smith GD, Holden A, Paydar N, Kiefer K. Chemical analysis of dyes on an Uzbek ceremonial coat: objective evidence for artifact dating and the chemistry of early synthetic dyes. Dyes Pigm. 2016;131:320-32. https ://doi.org/10.1016/i.dyepig.2016.04.019.

39. Troalen LG, Phillips AS, Peggie DA, Barranac PE, Hulme AN. Historical textile dyeing with Genista tinctoria L.: a comprehensive study by UPLC-MS/ MS analysis. Anal Methods. 2014;6:8915-23.

40. Tamburini $D$. Investigating Asian colourants in Chinese textiles from Dunhuang $\left(7^{\text {th }}-10\right.$ th century AD) by high performance liquid chromatography tandem mass spectrometry - towards the creation of a mass spectra database. Dyes Pigm. 2019;163:454-74. https://doi.org/10.1016/j. dyepig.2018.12.025.

41. Degano I, Mattonai M, Sabatini F, Colombini MP. A mass spectrometric study on tannin degradation within dyed woolen yarns. Molecules. 2019;24(12):2318.

42. Nabais P, Oliveira J, Pina F, Teixeira N, Freitas V, Brás NF, Clemente A, Rangel M, Silva AMS, Melo MJ. A 1000-year-old mystery solved: Unlocking the molecular structure for the medieval blue from Chrozophora tinctoria, also known as folium. Sci Adv. 2020;6(16):7772. https://doi.org/10.1126/ sciadv.aaz7772.

43. Liu J, Mouri C, Laursen R, Zhao F, Zhou Y, Li W. Characterization of dyes in ancient textiles from Yingpan. Xinjiang J Archaeol Sci. 2013;40(12):4444-9. https://doi.org/10.1016/j.jas.2013.06.034.

44. Degano I, Sabatini F, Braccini C, Colombini MP. Triarylmethine dyes: Characterization of isomers using integrated mass spectrometry. Dyes Pigm. 2019;160:587-96. https://doi.org/10.1016/j.dyepig.2018.08.046.

45. Nakamura R, Tanaka Y, Ogata A, Naruse M. Dye analysis of shosoin textiles using excitation-emission matrix fluorescence and ultraviolet-visible reflectance spectroscopic techniques. Anal Chem. 2009;81(14):5691-8. https://doi.org/10.1021/ac900428a.

46. Sasaki Y, Sasaki K. Analysis of protoberberines in historical textiles: determining the provenance of East Asian textiles by analysis of phellodendron. Preserv Sci. 2013;10:83-9.

47. Aceto M, Agostino A, Fenoglio G, Idone A, Gulmini M, Picollo M, Ricciardi P, Delaney JK. Characterisation of colourants on illuminated manuscripts by portable fibre optic UV-visible-NIR reflectance spectrophotometry. Anal Methods. 2014;6(5):1488-500. https://doi.org/10.1039/c3ay41904e.

48. Maynez-Rojas MA, Casanova-González E, Ruvalcaba-Sil JL. Identification of natural red and purple dyes on textiles by Fiber-optics Reflectance Spectroscopy. Spectrochim Acta Part A Mol Biomol Spectrosc. 2017;178:239-50. https://doi.org/10.1016/.saa.2017.02.019.

49. Fonseca B, Schmidt Patterson C, Ganio M, MacLennan D, Trentelman K. Seeing red: towards an improved protocol for the identification of madder-and cochineal-based pigments by fiber optics reflectance spectroscopy (FORS). Herit Sci. 2019;7(1):92. https://doi.org/10.1186/s4049 4-019-0335-1.

50. Mounier A, Le Bourdon G, Aupetit C, Lazare S, Biron C, Pérez-Arantegui J, Almazán D, Aramendia J, Prieto-Taboada N, Fdez-Ortiz de Vallejuelo S, Daniel F. Red and blue colours on 18th-19th century Japanese woodblock prints: In situ analyses by spectrofluorimetry and complementary non-invasive spectroscopic methods. Microchem J. 2018;140:129-41. https://doi.org/10.1016/.microc.2018.04.023.

51. Gulmini M, Idone A, Diana E, Gastaldi D, Vaudan D, Aceto M. Identification of dyestuffs in historical textiles: Strong and weak points of a non-invasive approach. Dyes Pigm. 2013;98(1):136-45. https://doi.org/10.1016/j.dyepi g.2013.02.010.

52. Villafana T, Edwards G. Creation and reference characterization of Edo period Japanese woodblock printing ink colorant samples using multimodal imaging and reflectance spectroscopy. Herit Sci. 2019;7(1):94. https://doi.org/10.1186/s40494-019-0330-6.

53. Tamburini D, Dyer J. Fibre optic reflectance spectroscopy and multispectral imaging for the non-invasive investigation of Asian colourants in Chinese textiles from Dunhuang (7th-10th century AD). Dyes Pigm. 2019;162:494-511. https://doi.org/10.1016/j.dyepig.2018.10.054.

54. Dyer J, Tamburini D, O'Connell ER, Harrison A. A multispectral imaging approach integrated into the study of Late Antique textiles from 
Egypt. PLoS ONE. 2018;13(10):e0204699. https://doi.org/10.1371/journ al.pone.0204699.

55. Vermeulen M, Muller EMK, Leona M. Non-invasive study of the evolution of pigments and colourants use in 19th-Century Ukiyo-e. Arts of Asia. 2020;50:2.

56. Tamburini D, Dyer J, Davit P, Aceto $M$, Turina V, Borla M, Vandenbeusch M, Gulmini M. Compositional and micro-morphological characterisation of red colourants in archaeological textiles from pharaonic Egypt. Molecules. 2019:24(20):3761.

57. Calà E, Benzi M, Gosetti F, Zanin A, Gulmini M, Idone A, Serafini I, Ciccola A, Curini R, Whitworth I, Aceto M. Towards the identification of the lichen species in historical orchil dyes by HPLC-MS/MS. Microchem J. 2019;150:104140. https://doi.org/10.1016/..microc.2019.104140.

58. Gulmini M, Idone A, Davit P, Moi M, Carrillo M, Ricci C, Bello FD, Borla M, Oliva C, Greco C, Aceto M. The "Coptic"textiles of the "Museo Egizio" in Torino (Italy): a focus on dyes through a multi-technique approach. Archaeol Anthropol Sci. 2016. https://doi.org/10.1007/s1252 0-016-0376-2.

59. Leona M, Winter J. Fiber optics reflectance spectroscopy: a unique tool for the investigation of Japanese paintings. Stud Conserv. 2001;46(3):153-62. https://doi.org/10.2307/1506806.

60. Douglas JG, Kavich G, Mori C, Wallace D, Barden R. Materials characterization of the Ruby Slippers from the 1939 classic film. Wizard Oz Herit Sci. 2018;6(1):49. https://doi.org/10.1186/s40494-018-0214-1.

61. Grzywacz CM, Wouters J, Bomin S, Yuquan F Conservation of Ancient Sites on the Silk Road - Asian Organic Colourants: a collaborative research project. In: Agnew N (ed) second international conference on the conservation of Grotto Sites, Mogao Grottoes, Dunhuang, China, 2004. Getty Conservation Institute,

62. Mouri C, Aali A, Zhang X, Laursen R. Analysis of dyes in textiles from the Chehrabad salt mine in Iran. Herit Sci. 2014;2(1):1-8. https://doi. org/10.1186/s40494-014-0020-3.

63. Pirok BWJ, den Uijl MJ, Moro G, Berbers SVJ, Croes CJM, van Bommel MR, Schoenmakers PJ. Characterization of dye extracts from historical culturalheritage objects using state-of-the-art comprehensive two-dimensional liquid chromatography and mass spectrometry with active modulation and optimized shifting gradients. Anal Chem. 2019. https://doi. org/10.1021/acs.analchem.8b05469.

64. Souto C. Analysis of early synthetic dyes with HPLC-DAD-MS - an important database for analysis of colorants used in cultural heritage. Lisbon: Univerisy of Lisbon; 2010.

65. Wouters J, Verhecken A. The coccid insect dyes: HPLC and computerized diode-array analysis of dyed yarns. Stud Conserv. 1989;34(4):189-200. https://doi.org/10.2307/1506286.

66. Cardon D. Into darkness: tannin plants. Natural dyes. Sources, tradition technology and science. London: Archetipe Publicatins Ltd; 2007. p. 409-484.

67. Hacke M. Weighted silk: history, analysis and conservation. Stud Conserv. 2008:53(sup2):3-15. https://doi.org/10.1179/sic.2008.53.supplement-2.3.

68. de Ferri L, Tripodi R, Martignon A, Ferrari ES, Lagrutta-Diaz AC, Vallotto D, Pojana G. Non-invasive study of natural dyes on historical textiles from the collection of Michelangelo Guggenheim. Spectrochim Acta Part A Mol Biomol Spectrosc. 2018;204:548-67. https://doi.org/10.1016/j. saa.2018.06.026.

69. Cardon D. Natural dyes. Sources, Tradition, Technology and Science: Archetype Publications Ltd., London; 2007.

70. Kirby J, van Bommel M, Verhecken A. Natural colorants for dyeing and lake pigments. London: Archtype Publications; 2014.

71. Montagner C, Bacci M, Bracci S, Freeman R, Picollo M. Library of UV-VisNIR reflectance spectra of modern organic dyes from historic patterncard coloured papers. Spectrochim Acta Part A Mol Biomol Spectrosc. 2011;79(5):1669-800. https://doi.org/10.1016/.saa.2011.05.033.

72. Sabatini F, Giugliano R, Degano I. Photo-oxidation processes of Rhodamine B: a chromatographic and mass spectrometric approach. Microchem J. 2018;140:114-22. https://doi.org/10.1016/j.microc.2018.04.018.

\section{Publisher's Note}

Springer Nature remains neutral with regard to jurisdictional claims in published maps and institutional affiliations.

\section{Submit your manuscript to a SpringerOpen ${ }^{\circ}$ journal and benefit from:}

- Convenient online submission

- Rigorous peer review

- Open access: articles freely available online

- High visibility within the field

- Retaining the copyright to your article

Submit your next manuscript at $\boldsymbol{\nabla}$ springeropen.com 